\title{
Surface water floods in Switzerland: what insurance claim records tell us about the damage in space and time
}

\author{
Daniel B. Bernet ${ }^{1}$, Volker Prasuhn ${ }^{2}$, and Rolf Weingartner ${ }^{1}$ \\ ${ }^{1}$ Institute of Geography \& Oeschger Centre for Climate Change Research \& Mobiliar Lab for Natural Risks, \\ University of Bern, Bern, Switzerland \\ ${ }^{2}$ Agroscope, Research Division, Agroecology and Environment, Zurich, Switzerland
}

Correspondence to: Daniel B. Bernet (daniel.bernet@giub.unibe.ch)

Received: 6 April 2017 - Discussion started: 10 April 2017

Revised: 4 August 2017 - Accepted: 23 August 2017 - Published: 29 September 2017

\begin{abstract}
Surface water floods (SWFs) have received increasing attention in the recent years. Nevertheless, we still know relatively little about where, when and why such floods occur and cause damage, largely due to a lack of data but to some degree also because of terminological ambiguities. Therefore, in a preparatory step, we summarize related terms and identify the need for unequivocal terminology across disciplines and international boundaries in order to bring the science together. Thereafter, we introduce a large $(n=63117)$, long (10-33 years) and representative (48\% of all Swiss buildings covered) data set of spatially explicit Swiss insurance flood claims. Based on registered flood damage to buildings, the main aims of this study are twofold: First, we introduce a method to differentiate damage caused by SWFs and fluvial floods based on the geographical location of each damaged object in relation to flood hazard maps and the hydrological network. Second, we analyze the data with respect to their spatial and temporal distributions aimed at quantitatively answering the fundamental questions of how relevant SWF damage really is, as well as where and when it occurs in space and time.

This study reveals that SWFs are responsible for at least $45 \%$ of the flood damage to buildings and $23 \%$ of the associated direct tangible losses, whereas lower losses per claim are responsible for the lower loss share. The Swiss lowlands are affected more heavily by SWFs than the alpine regions. At the same time, the results show that the damage claims and associated losses are not evenly distributed within each region either. Damage caused by SWFs occurs by far most frequently in summer in almost all regions. The normalized SWF damage of all regions shows no significant upward
\end{abstract}

trend between 1993 and 2013. We conclude that SWFs are in fact a highly relevant process in Switzerland that should receive similar attention like fluvial flood hazards. Moreover, as SWF damage almost always coincides with fluvial flood damage, we suggest considering SWFs, like fluvial floods, as integrated processes of our catchments.

\section{Introduction}

In Switzerland, there seems to be a growing awareness that just as overtopping rivers and lakes pose substantial flood risks for society, so too does flooding that takes place far away from watercourses. All across Europe, there are wellknown examples of such inland flood events. In 1988, for instance, a devastating flood occurred in Nîmes, France (e.g., Davy, 1990; Andrieu et al., 2004). In 2007, Hull, UK, was affected by flooding (e.g., Pitt, 2008; Coulthard and Frostick, 2010). One year later Dortmund, Germany, experienced widespread flooding (e.g., Grünewald, 2009). In 2011, the Danish capital Copenhagen was affected heavily by flooding (e.g., Haghighatafshar et al., 2014). The Swiss canton of Schaffhausen was affected severely in 2013 (e.g., Scherrer et al., 2013). On the same day in 2014, the Dutch capital Amsterdam (e.g., Gaitan et al., 2016; Spekkers et al., 2017) and Münster, Germany, experienced substantial flooding (Spekkers et al., 2017). These events in Europe share a common thread, which stems from their origin as inland floods, triggered by heavy precipitation, but are mostly unrelated to watercourses. 
As the definition of such floods is not straightforward, we adopt the term surface water floods (SWFs) for now, use it for non-fluvial floods in general and discuss the terminology in Sect. 2 in detail. Inherently, SWFs are not constrained to areas close to watercourses but can occur practically anywhere in the landscape (Kron, 2009). Consequently, such floods are difficult to document, study and forecast (e.g., Pitt, 2008; Steinbrich et al., 2016) and related data are scarce (e.g., Hankin et al., 2008; Douglas et al., 2010; Blanc et al., 2012; Grahn and Nyberg, 2017). Spekkers et al. (2014) mention the lack of data and the impact on small spatial scales as possible explanations why relatively little scientific research has been dedicated to such SWF in comparison to fluvial floods. In contrast, gray literature covers the topic of SWFs rather extensively, which is reflected by the availability of many guidelines and manuals discussing how to prepare for and manage such floods, for instance for single objects in Switzerland (Egli, 2007; Rüttimann and Egli, 2010) or on communal or regional levels in Germany (e.g., Castro et al., 2008; DWA, 2013; LUBW, 2016) or France (e.g., CEPRI, 2014). This might exemplify that the scientific flood risk community is indeed quite oblivious of resourceful gray literature (Uhlemann et al., 2013). In any case, it indicates that the topic is a concern for the people, the responsible authorities and other stakeholders. In order to reduce the risk, an effective approach is to focus on the physical protection of exposed objects (e.g., Kron, 2009; DWA, 2013). Although this strategy is certainly heading in the right direction, we have to be conscious about the basis on which current and future decisions concerning SWFs are made. Undoubtedly, the lack of quantitative data and studies hampers our process understanding (Grahn and Nyberg, 2017). Therefore, the underlying crucial question is "how can we reduce losses from natural hazards when we do not know ... when and where they occur?" (Gall et al., 2009).

Owing to vast river discharge time series, fluvial floods can be well predicted along gauged rivers (Steinbrich et al., 2016). As there are no such data concerning SWFs (Steinbrich et al., 2016), we must exploit other data sources in order to quantify the relevance of this flood type in space and time. Possible data sources include, but are not limited to, insurance claim records (e.g., Spekkers et al., 2013; Zhou et al., 2013; Moncoulon et al., 2014; Bernet et al., 2016; Grahn and Nyberg, 2017), disaster databases (e.g., Gall et al., 2009; Kron et al., 2012), press reports (e.g., Hilker et al., 2009) and interviews with or reports from affected people (e.g., Thieken et al., 2007; Evrard et al., 2007; Gaitan et al., 2016). All data sources are probably subjected to a varying degree of a socalled "threshold bias", which refers to the bias introduced due to varying damage inclusion criteria (Gall et al., 2009). Disaster databases only list events that exceeded predefined loss and/or fatality thresholds (Kron et al., 2012). Similarly, damage data based on news reports are subjected to unknown thresholds, as damage is only reported if it is found to be interesting enough. As interview campaigns are more likely to be initiated after devastating flood events, such data are biased towards more extreme events, as well (Elmer et al., 2010). Insurance claim records are likely affected the least by a threshold bias; as long as the related insurance policy stays the same, insured objects are not changing greatly over time and the deductibles are low or can be accounted for.

Damage claim records of insurance companies are therefore a profitable data source. Not surprisingly, they have been the base for several studies related to SWFs (e.g., Cheng et al., 2012; Spekkers et al., 2013, 2015; Zhou et al., 2013; Moncoulon et al., 2014; Bernet et al., 2016; Grahn and Nyberg, 2017). Unfortunately, insurance claim data are generally difficult to collect, since most insurance companies do not publish or provide loss data due to confidentiality issues (Boardman, 2010; Grahn and Nyberg, 2017). Furthermore, analyses based on such data are often impaired by the data's spatial or temporal aggregations. For instance, the limited usefulness of monthly aggregated data was demonstrated by Cheng et al. (2012), while Spekkers et al. (2014) pointed out some limitations of insurance data aggregated to administrative units, which do not have homogeneous topographical properties. As insurance companies usually do not assess and record detailed information for each damage claim, it is difficult to verify and differentiate the cause of each damage without at least knowing the explicit location of the damaged object. This is particularly important, as the corresponding data often cover different processes without explicit classification: for instance, Grahn and Nyberg (2017) had to exclude all damage records with dates that coincided with dates of known fluvial flood events to obtain a subset of SWF-related claims. Spekkers et al. (2013) chose a more elaborate method of applying a statistical filter based on the assumption that rainfall-related damage is clustered around wet days, while other causes of damage occur on any day throughout the year. Finally, even though many or even all buildings are insured against floods in several countries (e.g., in Sweden, as in Grahn and Nyberg, 2017; or in the Netherlands, as in Spekkers et al., 2014), usually only a subset of all objects is covered by the obtained data records. This is due to the fact that the objects are usually insured by many different companies, each having a different (unknown) market share. In addition, these shares are generally not constant over time either but may fluctuate heavily over time and space, as exemplified by Spekkers et al. (2014). These spatial and temporal changes need to be taken into account, which is often not trivial.

Luckily, most of these limitations are not applicable for damage claim records of the Swiss public insurance companies for buildings (PICBs). In Switzerland, PICBs are present in 19 out of the 26 cantons, whereas each company insures (almost) all buildings within the respective canton due to their monopoly position and because the insurance is generally mandatory for all house owners (e.g., Schwarze et al., 2011). Beside other natural hazards, the insurance covers damages caused by floods, which includes both fluvial floods 
and SWFs. Data records of PICBs are, therefore, exceptionally interesting for analyzing floods in general and SWFs in particular. Most PICBs have shown a general interest about research on this topic and, thus, were willing to provide flood claim records including the address of each damaged object.

Based on these data, the first aim of this study is to provide a method with which each claim can be classified as being caused by SWFs or fluvial floods. Second, based on the classified claim records, we aim to answer the fundamental question of how relevant damage caused by SWFs is, as well as where and when such damage occurs in space and time. The underlying data set stems from 13 PICBs and covers $48 \%$ of all buildings in Switzerland. Thus, the data set is representative of most of Switzerland, except for southern Switzerland (i.e., Western Inner Alps and Southern Alps). The analyzed data records all end in 2013 and extend back to at least 2004, but even up to 1981 depending on the corresponding PICB. As the PICBs, save a few exceptions, insure only property and not its contents, this study only considers damage to buildings. More specifically, this study is limited to direct tangible flood damages to buildings, i.e., monetary losses caused by the buildings' direct contact with flood water (Merz et al., 2010). Thereby, we acknowledge that these damages only constitute a portion of the total flood losses.

We have identified a lack of a common terminology concerning SWFs. Therefore, we dedicate the following Sect. 2 to a short overview of terms that are currently being used to address flood types that could be categorized as SWFs, as mentioned before. In Sect. 3 we describe the data in detail and introduce a method to differentiate SWF damage from fluvial flood damage. Thereafter, in Sect. 4, we present general characteristics of the number of claims and associated loss caused by SWFs in comparison to fluvial floods. Furthermore, we present the spatial and temporal characteristics of damage caused by SWFs in Switzerland during the last decades and discuss the results in Sect. 5. Finally, by providing concluding remarks, we conclude the study (Sect. 6).

\section{Terminology}

Flooding is a complex interlinked system, affecting many aspects of the physical, economic and social environments acting at different spatial and temporal scales (Evans et al., 2004; Barredo, 2009). As such, flooding involves a wide range of interconnected hydraulic subsystems and processes (Evans et al., 2004). Therefore, the classification of such a complex process like flooding is not trivial, particularly in practice. At the same time, many of the terms used to address flood types or involved hydrological processes in relation to SWFs are either used ambiguously in the literature or not well-defined. To prevent terminological ambiguities, we first introduce relevant hydrological processes, which helps to distinguish SWFs and fluvial floods. Thereafter, we elabo- rate related flood terms for a clearer definition of SWFs and provide recommendations for these terms' future reference.

SWFs are characterized by overland flow and ponding, which can be defined as follows. As precipitation reaches the land surface, different runoff generation mechanisms determine whether water starts to pond and whether overland flow is generated (e.g., Fiener et al., 2013). The water may then take several routes towards the stream channels (Ward and Robinson, 2000), as depicted in Fig. 1. The flow path along the land surface is sometimes ambiguously referred to as "surface runoff" but is better defined by the widely-used term "overland flow" (Ward and Robinson, 2000). However, in the literature, this distinction is inconsistently made, whereas either of the terms or even both are used. We adopt the term overland flow and, thereby, mean the transport of water downhill at the land surface as thin sheet flow or anastomosing braids of rivulets and trickles until the water reaches or is concentrated into recognizable streams (Chow et al., 1988; Ward and Robinson, 2000; Brutsaert, 2005).

The propagation and accumulation (i.e., ponding) of overland flow can be considered as a flood, which in the glossary of Field et al. (2012) is defined as "the overflowing of the normal confines of a stream or other body of water, or the accumulation of water over areas that are not normally submerged". As long as the water is directed towards a watercourse, but has not yet reached it, the flood can be regarded as a SWF, as defined later. Thus, the notable difference between a SWF and a fluvial flood is that in the former case, water is making its way towards a watercourse, whereas in the latter case flooding stems from a watercourse (Fig. 1).

As outlined previously, different flood terms are used in relation with SWFs. For a better distinction of these terms, we discuss each term and give recommendations about their future reference. A summary of the terms is presented in Table 1 .

"Pluvial floods" are caused by intense rainfall that, for whatever reason, cannot be drained by natural or artificial drainage systems, thereby ponds in local depressions or propagates along the surface as overland flow (Pitt, 2008; Hurford et al., 2012), before it possibly, but not necessarily, reaches or is concentrated into regular watercourses. The term pluvial flood is often used synonymously with SWF although, according to Falconer et al. (2009), SWFs have a broader meaning. Namely, in addition to pluvial floods as defined above, the term SWF also includes flooding from sewer systems, small open channels, culverted watercourses or flooding from groundwater springs (Hankin et al., 2008; Falconer et al., 2009). Therefore, SWFs can be regarded as the most general definition of rainfall-related (pluvial) floods. For future studies, we recommend using these two terms distinctively, depending on the corresponding context.

The term "muddy flooding" is well-established and refers to floods that are formed by muddy runoff from agricultural fields that damage adjacent properties downslope (Boardman, 2010; Ledermann et al., 2010). Here, the term is men- 


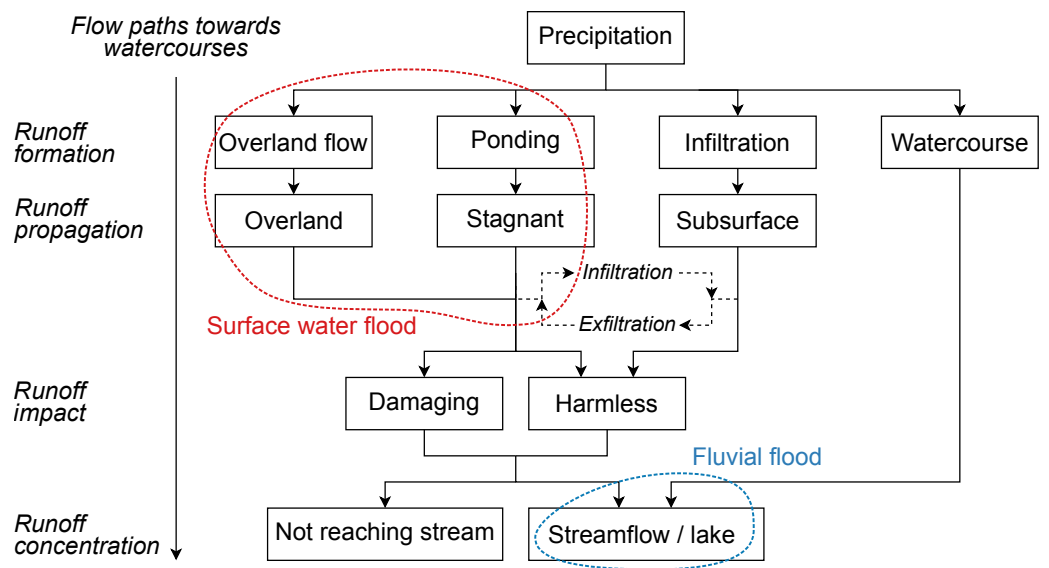

Figure 1. Interrelation of hydrological processes that may lead to a surface water flood (red ring) and/or a fluvial flood (blue ring).

Table 1. Summary of flood terms related to surface water floods. The column "Type" indicates whether the corresponding term refers to a rainfall-related (pluvial) or fluvial flood type. The information is taken from the sources cited in Sect. 2.

\begin{tabular}{|c|c|c|}
\hline Flood term & Type & Main sources \\
\hline Surface water flood & Pluvial & $\begin{array}{l}\text { Water that could not be drained; surcharged sewer or culverted } \\
\text { watercourse; overtopping open channel; groundwater spring }\end{array}$ \\
\hline Pluvial flood & Pluvial & Water that could not be drained \\
\hline Sewer flood & Pluvial & Sewer surcharge or backup \\
\hline Muddy flood & Pluvial & Muddy runoff from agricultural fields \\
\hline Urban flood & Fluvial/pluvial & Any source contributing to inundation in urban areas \\
\hline Flash flood & Fluvial/(pluvial*) & Watercourses/(see surface water flood*) \\
\hline
\end{tabular}

* Recently increasingly used to address pluvial flood types.

tioned to point out that this flood type is implicitly included by the definition of SWFs and pluvial floods.

The term "flash floods" is used quite ambiguously in the literature (van Campenhout et al., 2015). Traditionally, it refers to fluvial floods triggered by short, intense and local storm events (e.g., Merz and Blöschl, 2003; Gaume et al., 2009; Falconer et al., 2009; Ruiz-Villanueva et al., 2012). However, the term may include other causes as well (Castro et al., 2008; Priest et al., 2011; Gourley et al., 2013). Moreover, the term has increasingly been used in relation to pluvial flood types (see Kron et al., 2012; Steinbrich et al., 2016). Apparently, the term is often used in this context by publications in German using the translated term Sturzflut (see Castro et al., 2008; Kron, 2009; DWA, 2013). For future reference, we recommend adopting the term flash flood only in the traditional sense and use the applicable term, i.e., pluvial flood or SWF, for all other cases.

The terms "urban" or "intra-urban" are mainly used as a specifier of the geographical extent of a flood or the main focus of the corresponding study (see Evans et al., 2004; Andrieu et al., 2004; Douguédroit, 2008; Hankin et al., 2008; DWA, 2013; Zhou et al., 2013). If applicable, the use of this term as a specifier in combination with other flood terms can be recommended, since the corresponding flood type is thus better defined. However, we suggest refraining from the isolated usage of the term, as in "urban flood" for instance, since the flood type is thereby not unequivocally defined. In case the term is intentionally used in such a broad context, we recommend mentioning this explicitly.

Finally, we deem it necessary to introduce a further distinction for a better understanding of this study's results. Namely, it is important to note that the term "flood" is sometimes implicitly used in the hydrological sense but sometimes also in the context of "damaging floods" (Barredo, 2009). In the former case, any inundation of land is considered, while in the latter case the flood necessarily interacts with the societal system causing adverse effects (Barredo, 2009). Thus, our results represent only damaging floods, as this study is based solely on the exploitation of damage data. Note that this distinction is visualized in Fig. 1.

\section{Materials and methods}

The compiled data set is based on flood damage claim records from 14 different PICBs. In addition, we obtained similar records from Swiss Mobiliar, a cooperative insur- 
ance company (CIC). The corresponding data records were solely used to support the parametrization of the classification scheme. Thus, they were not part of the data analyses, as elaborated in more detail in Sect. 3.1.

As mentioned before, each PICB holds a monopoly position and, thus, insures virtually every single building within the respective canton against various natural hazards including flooding. Therefore, damage caused by water entering the building envelope at the surface is insured, while damage associated with direct intrusion of groundwater or backwater from the sewer, as well as flooding from dams or other artificial water structures, is generally excluded. As a consequence, water-related damage covered by PICBs is caused by either SWFs or fluvial floods, whereas the insurance companies themselves do not differentiate the two processes (Imhof, 2011). Therefore, similar to other studies (e.g., Spekkers et al., 2013, 2015; Grahn and Nyberg, 2017), the data have to be classified first. However, in contrast to the aforementioned studies, the claim records were provided in a spatially explicit way, enabling a classification based on each claim's geographical context.

Following the data processing procedure depicted in Fig. 2, we first describe the compiled data set and the harmonization and geocoding thereof (Sect. 3.1). Then we introduce a method to differentiate claims associated with SWFs and fluvial floods (Sect. 3.2) and, thereafter, we discuss the necessary normalizations of the data (Sect. 3.3). Note that the classification scheme is described as generally as possible to make its application to other contexts and countries as straightforward as possible. However, it could not be prevented that the classification scheme is adapted to some national characteristics, in particular concerning the properties of the considered Swiss flood maps. The specific input data for each data processing step listed in Fig. 2 are described in detail in Table 2.

\subsection{Data}

Figure 3 gives an overview of the compiled data set and illustrates all 19 cantons with a PICB, while the 14 PICBs that provided data are highlighted additionally. As the cantons' borders have mostly administrative meaning, we adapted the natural landscape units from Grosjean (1975), while constraining the borders to hydrological catchment boundaries. In this study, the data are analyzed with respect to these regions (Fig. 3). Overall, 43-100\% of the buildings are covered by our data set, with the exception of the Western Inner Alps $(0 \%)$ and the Southern Alps $(6 \%)$. The low values of the latter two regions are owed to the fact that practically no buildings are insured by a PICB within these areas. Consequently, these areas are excluded from this study's analyses, even though some claims provided by the CIC covered this region.

The CIC's data contain flood damage claim records of content and, additionally, of property in cantons with no PICB.

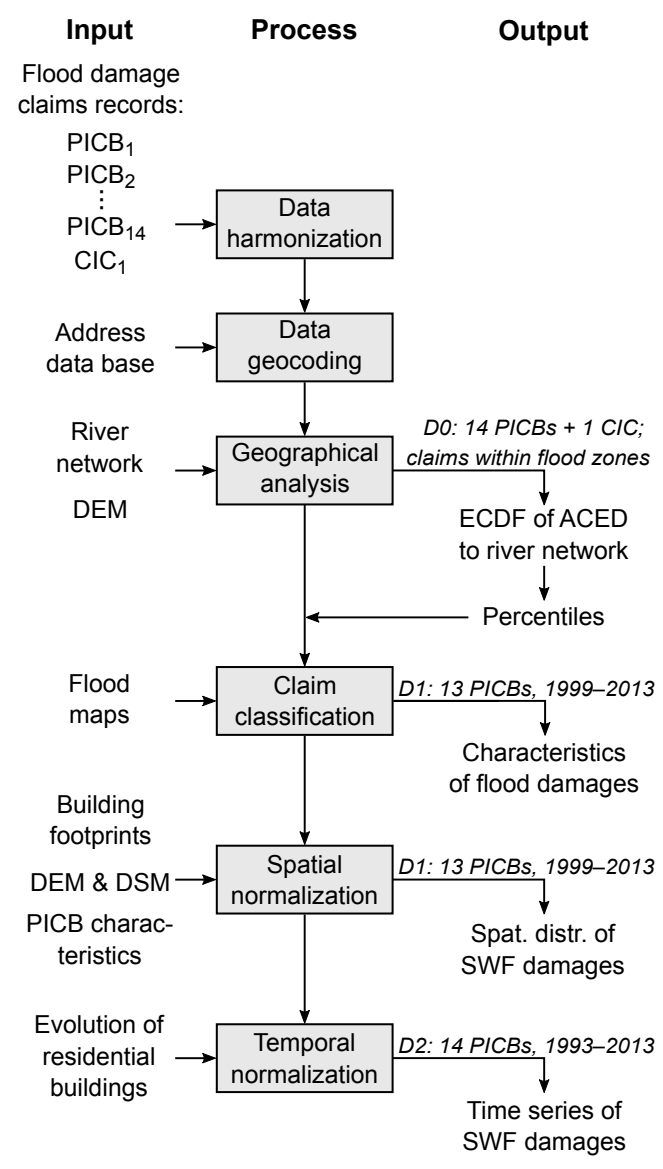

Figure 2. Illustration of the main data processing steps (boxes) and the required input data, which are further specified in Table 2. D0, D1 and D2 refer to the data subsets, which were used to produce the output, illustrated by this study's tables and figures. Note that D0 constitutes the complete data set including data from 14 PICBs in addition to data from a CIC, whereas D1 and D2 consist of PICB data only, limited to the indicated periods (see also Table 3 ). The empirical cumulative distribution function (ECDF) and the altitude constrained Euclidean distance (ACED) between each claim and the next river are abbreviated (see Sect. 3.2).

These records have quite similar characteristics as the data provided by the PICBs but are not limited to certain cantons and, thus, extend over the whole of Switzerland. However, unlike PICBs, the CIC does not hold a monopoly position. Consequently, the corresponding data records cover only the objects that are not insured by another private insurance company. Such records that are subjected to certain (unknown) market shares are much more challenging to interpret, as pointed out in the introduction. Nevertheless, the data are useful to set up the classification scheme because every additional claim generally increases the method's robustness (see Sect. 3.2). The data from the CIC are part of the data set D0, which is used solely for parametrizing the classification scheme (see Table 3 and Fig. 2). 
Table 2. Summary of the specific input data used for the classification and normalization of the flood damage claims, in the order of appearance in Fig. 2. Note that all links were last checked on 3 March 2017.

\begin{tabular}{|c|c|c|c|}
\hline Input data & Name & Description & Source \\
\hline $\begin{array}{l}\text { Address data } \\
\text { base }\end{array}$ & $\begin{array}{l}\text { GeoPost } \\
\text { Coordinates }\end{array}$ & $\begin{array}{l}\text { Register of all geocoded postal addresses of } \\
\text { Switzerland as of } 2015 \text {, provided by the na- } \\
\text { tional postal service Swiss Post }\end{array}$ & $\begin{array}{l}\text { https://www.post.ch/en/ } \\
\text { business/a-z-of-subjects/ } \\
\text { maintaining-addresses-and-using-geodata/ } \\
\text { address-and-geodata }\end{array}$ \\
\hline River network & swissTLM3D & $\begin{array}{l}\text { Feature TLM_FLIESSGEWAESSER of the } \\
\text { Swiss topographical landscape model, v1.4, } \\
\text { provided by the Federal Office of Topogra- } \\
\text { phy (swisstopo) }\end{array}$ & $\begin{array}{l}\text { https://shop.swisstopo.admin.ch/en/ } \\
\text { products/landscape/tlm3D }\end{array}$ \\
\hline $\begin{array}{l}\text { Flood hazard } \\
\text { maps (main) }\end{array}$ & $\begin{array}{l}\text { Flood hazard } \\
\text { maps }\end{array}$ & $\begin{array}{l}\text { Official Swiss (fluvial) flood hazard maps } \\
\text { (e.g., Zimmermann et al., 2005; de Moel } \\
\text { et al., 2009) compiled in a single data set } \\
\text { and provided by Swiss Mobiliar }\end{array}$ & $\begin{array}{l}\text { https://www.bafu.admin.ch/bafu/en/home/ } \\
\text { topics/natural-hazards/state/maps.html }\end{array}$ \\
\hline $\begin{array}{l}\text { Flood map } \\
\text { (ancillary) }\end{array}$ & Aquaprotect & $\begin{array}{l}\text { Simple flood map for the whole of Switzer- } \\
\text { land, produced by the Swiss Federal Office } \\
\text { for the Environment (FOEN) in collabora- } \\
\text { tion with the Swiss reinsurance company } \\
\text { Swiss Re }\end{array}$ & $\begin{array}{l}\text { https://www.bafu.admin.ch/bafu/ } \\
\text { en/home/state/data/geodata/ } \\
\text { natural-hazards--geodata.html }\end{array}$ \\
\hline $\begin{array}{l}\text { Building } \\
\text { footprints }\end{array}$ & swissTLM3D & $\begin{array}{l}\text { Feature TLM_GEBAEUDE_FOOTPRINT; } \\
\text { see river network for details }\end{array}$ & see river network \\
\hline $\begin{array}{l}\text { Digital eleva- } \\
\text { tion model }\end{array}$ & swissALTI3D & $\begin{array}{l}\text { High-precision digital elevation model } \\
\text { (DEM) as of } 2013 \text { with a regular grid size } \\
\text { of } 2 \text { by } 2 \mathrm{~m} \text {, provided by swisstopo }\end{array}$ & $\begin{array}{l}\text { https://shop.swisstopo.admin.ch/en/ } \\
\text { products/height_models/alti3D }\end{array}$ \\
\hline $\begin{array}{l}\text { Digital surface } \\
\text { model }\end{array}$ & DSM & $\begin{array}{l}\text { Digital surface model, last updated in } 2008 \text {, } \\
\text { provided by swisstopo }\end{array}$ & $\begin{array}{l}\text { https://shop.swisstopo.admin.ch/en/ } \\
\text { products/height_models/DOM }\end{array}$ \\
\hline $\begin{array}{l}\text { Residential } \\
\text { buildings }\end{array}$ & BDS & $\begin{array}{l}\text { Buildings and dwellings statistic, as of } \\
\text { 2013, provided by the Swiss Federal Statis- } \\
\text { tical Office }\end{array}$ & $\begin{array}{l}\text { https://www.bfs.admin.ch/bfs/en/home/ } \\
\text { statistics/construction-housing/surveys/ } \\
\text { gws2009.assetdetail.8945.html }\end{array}$ \\
\hline $\begin{array}{l}\text { PICB charac- } \\
\text { teristics }\end{array}$ & - & $\begin{array}{l}\text { Total number of insured buildings and total } \\
\text { sum insured of each considered PICB as of } \\
\text { the end of 2013, taken from their annual re- } \\
\text { ports }\end{array}$ & available online for most PICBs \\
\hline
\end{tabular}

The minimal information of each flood damage claim includes the damage date, the location of the damage (address or coordinates) and the associated direct tangible loss to the respective building. As the claim data stem from 15 different data sources (14 PICBs and data from a CIC), the provided raw data are heterogeneous and need to be harmonized first, as indicated in Fig. 2 (see Bernet et al., 2016, for details). During this procedure, the data were quality checked. Obvious errors such as address misspellings or flipped coordinate pairs were corrected. Furthermore, we removed duplicated entries and records with incomplete (e.g., missing address) or invalid data (e.g., invalid damage date). In terms of loss, we assessed total loss values, i.e., the sum of the registered pay offs and applicable deductibles. Since the insurance coverage is not limited to an upper bound, the maximal total loss for each building equals its sum insured. Applicable deductibles vary between the different PICBs, whereas no deductibles at all, a fixed participation of a few hundred Swiss francs or a variable participation of $10 \%$ within a fixed range with a maximum value of CHF 4000 are applied. Finally, the total loss values were corrected for inflation as of 2013 by applying the respective construction output price index considered by each PICB, in case the source data had not been indexed already.

During the next step, each damage claim is geocoded (Fig. 2). The coordinates of each damaged building could be obtained by matching the corresponding address with a geocoded register of all Swiss postal addresses (see Table 2). Notably, only the claims with an unique match were analyzed later. As the data quality of the addresses varies among the 
Table 3. Characterization of the claim records reporting flood damage to buildings provided by 14 different PICBs in addition to claims of content and buildings provided by a CIC. The absolute number of localized claims is presented in addition to the fraction relating to the total number of claims. The columns D0, D1 and D2 each represent a data subset and indicate the temporal coverage of each data record (D0) or a specific limitation thereof (D1 and D2).

\begin{tabular}{llrrrr}
\hline Company & Canton & Localized claims & D0 & D1 & D2 \\
\hline PICB $_{1}$ & Solothurn (SO) & $4456(90 \%)$ & $1981-2013$ & $1993-2013$ & $1999-2013$ \\
PICB $_{2}$ & Glarus (GL) & $463(56 \%)$ & $1982-2013$ & $1993-2013$ & $1999-2013$ \\
PICB $_{3}$ & Fribourg (FR) & $5494(96 \%)$ & $1983-2013$ & $1993-2013$ & $1999-2013$ \\
PICB $_{4}$ & Nidwalden (NW) & $1383(97 \%)$ & $1987-2013$ & $1993-2013$ & $1999-2013$ \\
PICB $_{5}$ & Neuchâtel (NE) & $1959(99 \%)$ & $1988-2013$ & $1993-2013$ & $1999-2013$ \\
PICB $_{6}$ & Aargau (AG) & $9024(73 \%)$ & $1989-2013$ & $1993-2013$ & $1999-2013$ \\
PICB $_{7}$ & Grisons (GR) & $2258(95 \%)$ & $1991-2013$ & $1993-2013$ & $1999-2013$ \\
PICB $_{8}$ & Basel-Stadt (BS) & $243(86 \%)$ & $1992-2013$ & $1993-2013$ & $1999-2013$ \\
PICB $_{9}$ & Lucerne (LU) & $7848(79 \%)$ & $1993-2013$ & $1993-2013$ & $1999-2013$ \\
PICB $_{10}$ & Vaud (VD) & $3275(56 \%)$ & $1994-2013$ & $1994-2013$ & $1999-2013$ \\
PICB $_{11}$ & Basel-Landschaft (BL) & $1820(89 \%)$ & $1999-2013$ & $1999-2013$ & $1999-2013$ \\
PICB $_{12}$ & Jura (JU) & $809(83 \%)$ & $1999-2013$ & $1999-2013$ & $1999-2013$ \\
PICB $_{13}$ & St Gall (SG) & $4764(74 \%)$ & $1999-2013$ & $1999-2013$ & $1999-2013$ \\
PICB $_{14}$ & Zug (ZG) & $761(85 \%)$ & $2004-2013$ & $2004-2013$ & \\
CIC $_{1}$ & All (build. \& cont.) & $18560(100 \%)$ & $2004-2014$ & & \\
\hline Total & & $63117(85 \%)$ & 63117 & 40233 & 31711 \\
\hline
\end{tabular}

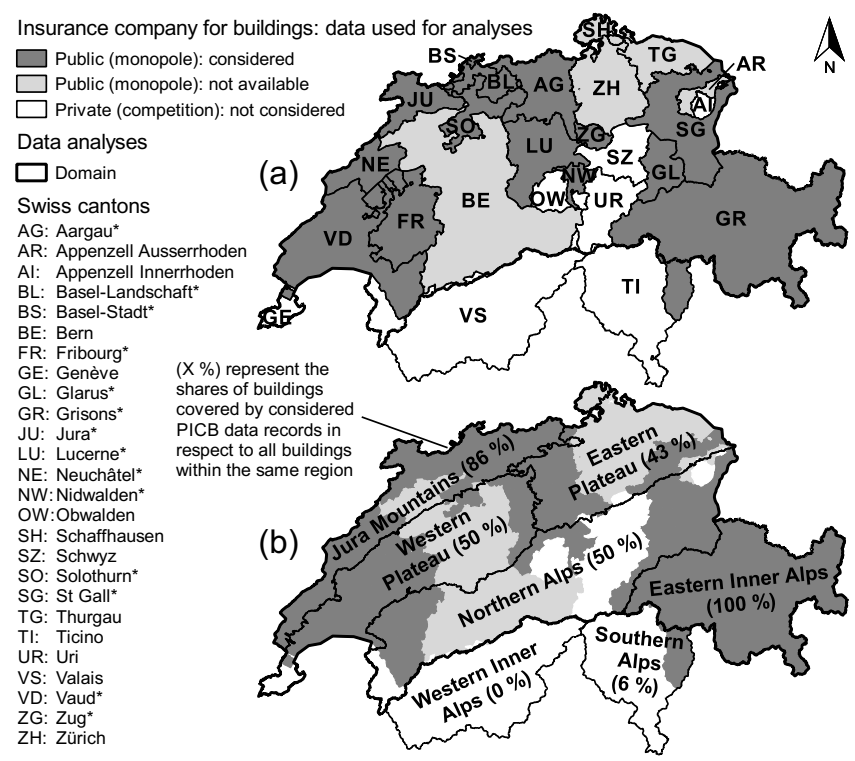

Figure 3. Overview of the compiled data set D1 (see Table 3). (a) Cantons with and without a PICB and an indication of which PICBs provided data. The latter are additionally marked with an asterisk (*) in the legend. (b) Natural landscape units based on Grosjean (1975), which are used to analyze the data on a regional scale. As almost no buildings are insured by PICBs within the Western Inner Alps or the Southern Alps, these two regions are excluded from the data analyses, as indicated by the domain. different PICBs, the amount of claims that could be localized at the building level varies as well (Table 3). Nevertheless, most of all PICB claims (79\%) could be localized. A summary of the compiled data subsets is given in Table 3 .

\subsection{Classification}

The basic idea behind the classification scheme is simple: in case a building (and/or its content) has been damaged by flooding and was located far away from any watercourse, it is very likely that the damage was caused by a SWF. The opposite is not necessarily true: overland flow is propagating over the land surface towards the watercourses and might cause damage along the flow path until it reaches the next watercourse (Fig. 1). Thus, for damaged objects close to a watercourse it is difficult to deduce the responsible flood type without studying each case in detail. Given the size of the data set, detailed manual classification is not practical, in addition to the fact that the data generally do not contain additional information about the responsible damage causes.

In order to classify the claims pragmatically, we exploit the damage claims' known locations as follows: we assume that the dominant damage process in known fluvial flood zones are fluvial floods and, thus, damaged objects located within such zones were likely affected by this process. As these damage claims are inherently clustered around watercourses, we make use of this characteristic by assessing the distance between these claims and the next river. We then classify the damage claims outside of known flood zones based on how their own distance to the next river relates to the typical distances obtained from fluvial flood claims. However, the 
Table 4. Percentile values ( $d_{X}$, where $X$ stands for the $X$ th percentile) obtained from the ECDF of ACEDs between claims within flood zones and the closest river for each respective region. The column $n$ represents the sample size of each underlying ECDF.

\begin{tabular}{lrrrrr}
\hline Region & $n($ no. $)$ & $d_{25}(\mathrm{~m})$ & $d_{50}(\mathrm{~m})$ & $d_{75}(\mathrm{~m})$ & $d_{99}(\mathrm{~m})$ \\
\hline Jura Mountains & 5508 & 58 & 135 & 315 & 1360 \\
Western Plateau & 5810 & 47 & 108 & 237 & 1259 \\
Eastern Plateau & 10167 & 56 & 135 & 285 & 1084 \\
Northern Alps & 7532 & 65 & 137 & 298 & 1198 \\
Eastern Inner Alps & 891 & 29 & 61 & 112 & 643 \\
\hline
\end{tabular}

question is how this distance should be measured and how a representative cutoff distance can be determined.

We tested different distance measures, whereas the $\mathrm{Eu}-$ clidean distance performed well, for instance, but neglected topography altogether. For instance, a building on a ridge can be associated with a short Euclidean distance to the next river, in spite of being safe from river flooding due to the building's elevated location. We therefore chose the following approach to address this issue, while at the same time making use of the Euclidean distance's simplicity: before calculating the Euclidean distance to the next river, we first hide all parts of the river network that are located at lower altitudes than the respective object. For this task, we create a raster mask indicating cells that are located at lower altitudes than the corresponding object, based on a digital elevation model (DEM; Table 2). The Euclidean distance to the river network is then assessed by using the raster mask, which hides all river sections at lower altitudes than the respective object. The obtained quantity is hereafter referred to as the altitude constrained Euclidean distance (ACED).

Typical distances for all fluvial flood damage claims can then easily be obtained by analyzing the ACEDs of all claims located within known flood zones. For that matter, we selected all claims within such flood zones and compiled the empirical cumulative distribution function (ECDF) of the ACEDs. Based on the large data set, we can be confident that the claims located farther away from the closest river than the 99th percentile of the respective ECDF were caused by SWFs. Considering that fluvial floods become generally more probable the closer we get to the rivers, we chose evenly spaced percentiles, i.e., the 25th, the 50th, 75th and the 99th percentile. The percentiles are calculated for each region separately (Table 4). As the regions themselves represent areas with similar orographic and climatic characteristics (Grosjean, 1975), we thereby implicitly take these regional geographical characteristics into account.

Inherently, the flood claims also include damage caused by overflowing lakes, which could not be distinguished easily from fluvial floods. Consequently, damage related to lakes will be associated with a certain distance to the next river, even though the corresponding river was not the cause of the damage. A visual check of such claims revealed that they

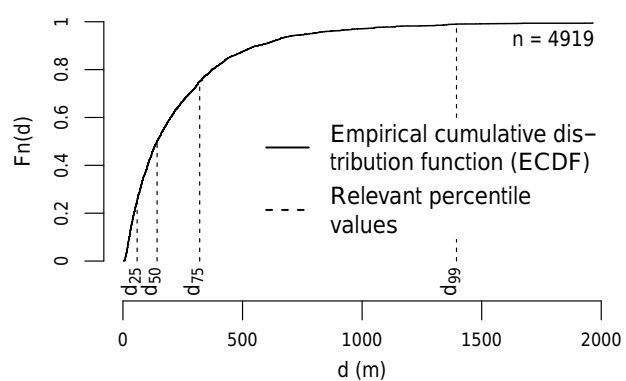

Figure 4. ECDF of all ACEDs of the claims within flood zones in the Jura Mountains. Such ECDFs were compiled separately for all five analyzed regions in Switzerland (see Fig. 3). The corresponding percentiles are used for the classification of the claims (see Fig. 5) and are listed in Table 4.

tend to be located closer to the corresponding lake than the next watercourse. Technically, this shifts the ECDF of distances to the right and, accordingly, renders higher percentile values (see Fig. 4 and Table 4). In turn, applying the classification scheme with increased percentile values leads to more claims being associated with fluvial floods instead of SWFs. However, as the number of claims associated with overflowing lakes is low in comparison to claims associated with overtopping rivers, it is safe to assume that this influence is negligible. At most, it might lead to a slightly more conservative classification of SWF claims. Besides, the claims associated with overflowing lakes are directly and correctly classified as fluvial floods, because the hazard of overflowing lakes is consistently considered in the fluvial flood maps (see Fig. 5).

Using the precompiled percentiles (Table 4) and fluvial flood maps (Table 2) as input, the damage claims can then be classified by means of the classification scheme presented in Fig. 5. Five different classes are differentiated, ranging from most likely surface water flood (A) to most likely fluvial flood (E) (see Fig. 5). The qualitative confidence levels reflect that in general it is becoming gradually more unlikely that an object is affected by fluvial floods the farther away an object is located from a river.

As outlined in Fig. 5, we make use of two particular fluvial flood maps, i.e., the "official" Swiss flood hazard maps (Zimmermann et al., 2005; de Moel et al., 2009) and an ancillary map available for the whole of Switzerland called Aquaprotect (see Table 2). As for the Swiss flood hazard maps, Swiss Mobiliar collected all available maps from each canton and, in agreement with the responsible authorities, provided the data as of December 2016. The data contain the perimeters for which fluvial flood hazards have been mapped in detail. Within these perimeters, the fluvial flood hazards are indicated using four different so-called danger levels (de Moel et al., 2009), whereas we define the flood hazard zone as the combined area of low, medium and elevated danger, while excluding the area categorized as residual danger (see Zimmermann et al., 2005). As indicated by de Moel et al. (2009), 


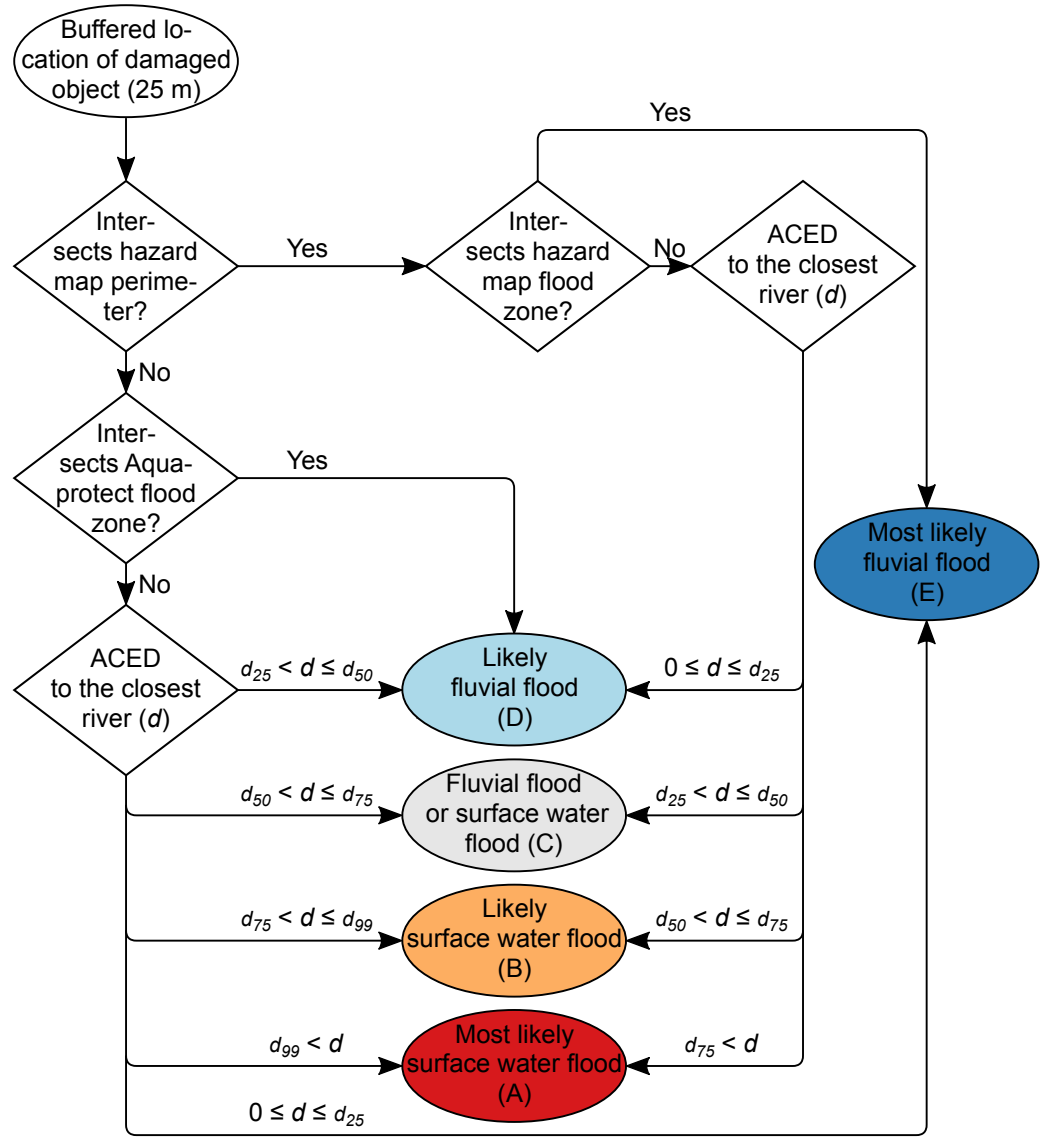

Figure 5. Classification scheme applied to all localized damage claims. As indicated, each claim's point location is buffered by $25 \mathrm{~m}$, corresponding to an average building width. This accounts for the fact that in reality the buildings have a certain spatial extent. The claims are classified as most likely fluvial floods (E) when their buffered location intersect the hazard map flood zone or as likely fluvial floods (D) when they intersect the ancillary flood map Aquaprotect. The different qualitative confidence levels reflect the level of detail of the two different flood maps (see Table 2). In all other cases, the specific ACED $(d)$ of each claim is compared to the typical ACEDs of fluvial flood damage $\left(d_{25}, d_{50}, d_{75}\right.$ and $d_{99}$; see Table 4$)$. The classification scheme is further illustrated in Fig. 6.

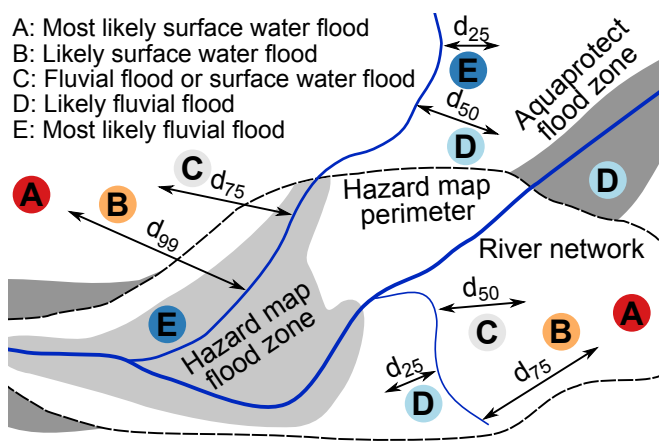

Figure 6. Schematic visualization of the classification scheme. Note that each of the shown classified damage claims corresponds to 1 of the 11 unique paths of the classification scheme depicted in Fig. 5. the flood hazard maps are available for almost the entire Swiss territory. In fact, $88 \%$ of all claims are covered by the flood hazard maps as of 2016; i.e., they are located within the hazard maps' perimeters. The number has increased rapidly in recent years. Nevertheless, there are still cantons where more than $60 \%$ of the claims are located outside of the perimeters. Thus, to increase the coverage, we used the aforementioned map called Aquaprotect (see Table 2). It contains coarse fluvial flood extension maps compiled for return periods of 50, 100, 250 and 500 years. We chose the map representing a return period of 250 years, as it best matches the return period of up to 300 years considered by the flood hazard maps. As indicated in Fig. 6, Aquaprotect is only used for the territory not covered by the flood hazard maps; namely, the hazard map perimeters have been extracted from the Aquaprotect layer using common GIS tools. 
It should be noted that the areas not covered by flood zones, i.e., the hazard-free zones, have similar implications for the two different sources. Consistently, headwaters and small tributaries are not covered by Aquaprotect, yet no information about the specific exclusion criterion could be found. This also holds true for the flood hazard maps, as the study of a few examples revealed. Moreover, the flood hazard maps are produced independently by the regional governments (de Moel et al., 2009), i.e., cantons. Consequently, the applied methods vary between the different cantons and, thus, general statements cannot be made. Nevertheless, the level of detail of the Swiss flood hazard maps far exceeds the one of Aquaprotect. We considered this by empirically choosing lower percentile levels for claims located within the flood hazard perimeters, as shown in Figs. 5 and 6.

\subsection{Normalizations}

Reported increasing trends of flood losses (e.g., Kron et al., 2012; Grahn and Nyberg, 2017) might be misleading. In fact, there is evidence that increasing flood losses are mainly owed to socioeconomic development rather than trends in the flood processes itself (Barredo, 2009). Increasing losses caused by natural hazards such as flooding can, thus, mostly be attributed to increasing population and expansion into hazardous areas (e.g., Cutter and Emrich, 2005; Barredo, 2009; Bouwer, 2011; Kundzewicz et al., 2014), increasing property values and diminishing awareness about such hazards (Kundzewicz et al., 2014) and, additionally, better documentation of cases of damage in the more recent past (Gall et al., 2009). Consequently, the loss data need to be normalized with regard to such effects when the natural process rather than the product with the socioeconomic background is of interest. The most fundamental normalization is to adjust past losses to the current values (Kron et al., 2012). However, the more difficult part is to remove the influence of socioeconomic development on the observed number of damage claims and the associated loss. In addition, the consideration of a change in the exposed objects' vulnerabilities is even more difficult (Bouwer, 2011).

In this study, the values are adjusted for inflation during the harmonization procedure (Sect. 3.1). Furthermore, the absolute damage data are normalized in space by relating them to the number of buildings and the sum insured as of 2013 (Appendix A1). Finally, by normalizing the data over time (Appendix A2), we obtain a time series of normalized damage caused by SWFs. At the same time, we assume that the buildings' vulnerabilities with regards to SWFs have remained constant within the last decades. This assumption seems appropriate since SWFs have not been considered by any building code so far. Moreover, the analyzed period is several times shorter than the regular life span of Swiss buildings. Lastly, we apply the seasonal Mann-Kendall test (Hirsch et al., 1982) with a significance level of 0.1 for the re- sulting $p$ value to test whether the number of damage claims and associated losses have increased or decreased over time.

\subsection{Validation}

There are few data sets available with which the claims' classification or normalization could be validated. Hereafter, the exploitation of available data sources for this purpose is elaborated.

First of all, the canton of Lucerne published an overland flow depth map in 2016 stemming from hydrodynamic simulations based on the method described by Kipfer et al. (2012). However, the map indicating categorized flow depth polygons is not suitable for a quantitative validation of the claims' classification. The polygons all indicate a minimal flow depth of $0.015 \mathrm{~m}$ and are very dense. In fact, $67 \%$ of all building footprints of the canton of Lucerne intersect such a polygon, whereas only $6.5 \%$ of the footprints are farther than $10 \mathrm{~m}$ away from the closest polygon. Consequently, neither a quantitative nor a visual relationship could be found between each claim's class and the categorized flow depths.

Secondly, hazard indication maps regarding overland flow are available from two of the 14 cantons covered by our data set, i.e., from the canton of Basel-Landschaft and Aargau. However, the hazard of overland flow was not assessed comprehensibly judging by the technical reports that are publicly available. In some subregions, the hazard was assessed by means of GIS analysis and/or based on known past events, or the hazard was not considered at all. Consequently, these maps did not allow a direct quantitative validation either.

In fact, a systematic validation of the classification was not feasible due to the large number of claims and the lack of suitable data. Nevertheless, the classification was checked visually, drawing from the input data including flood maps, the river network, the DEM, etc. (see Table 2), in addition to the before-mentioned hazard indication maps. The results of this qualitative and visual comparison are summarized in Sect. 4.1.

However, unlike for the claims' classification, it was possible to verify the overall performance of the applied normalizations. Specifically, we could compare our normalized data set with virtually the same source data that had been normalized with the corresponding property data. The reference data are a subset of the data shown in Imhof (2011). The normalization's validation is presented in Sect. 4.1, as well.

\section{Results}

After presenting the validation's results (Sect. 4.1), we quantify, characterize and compare the damage caused by SWFs with damage caused by fluvial floods (Sect. 4.2). In the following, we present the spatial distribution of SWF damage (Sect. 4.3) and show how the damage evolved within the last 20 years (Sect. 4.4). 


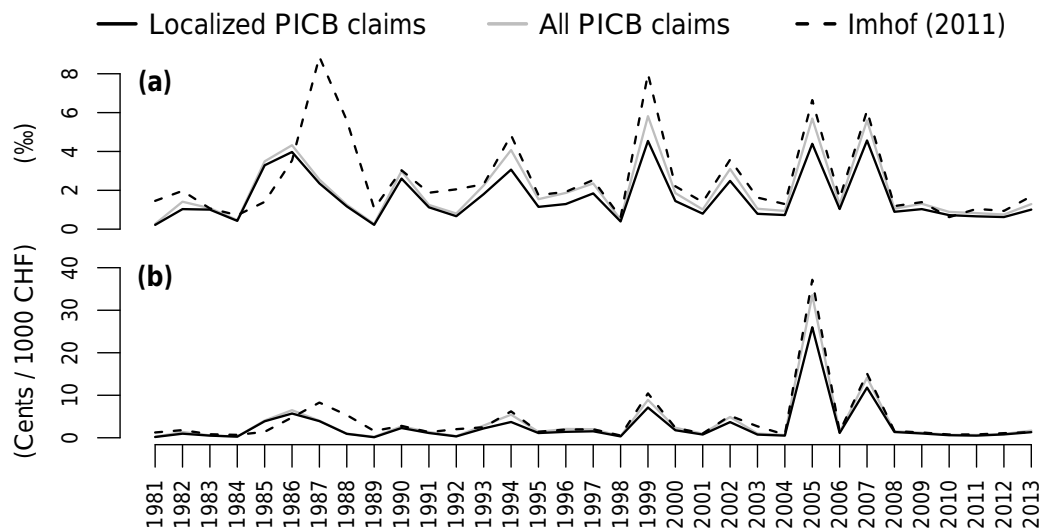

Figure 7. Validation of the normalized damage data. (a) Aggregated normalized number of claims in relation to the total number of insured buildings. As a reference, data stemming from a subset of the data presented in Imhof (2011) are shown. As the data are spatially aggregated, all the data including claims without a geocode could be shown, in addition to the localized claims. (b) Aggregated normalized loss in relation to the total sum insured.

Note that in the following damage claims classified as A or B, i.e., (most) likely surface water floods, are regarded as damage caused by SWFs, if not stated otherwise. Analogously, damage claims classified as D or E, i.e., (most) likely fluvial floods, are counted as damage caused by fluvial floods. Claims of class C, i.e., fluvial flood or surface water flood, are not counted for one or the other flood type unless total values are presented.

\subsection{Validation}

The visual comparison of the classified damage claims with overland flow indication maps of the canton of BaselLandschaft and Aargau revealed that many claims associated with overland flow are clearly located outside areas for which the hazard of overland flow have been assessed or documented. In contrast, the indicated hazard zones were either covering SWF claims or were at least located close to such claims. This might highlight that the corresponding claims were the cause for the delineation of these zones, but at the same time it also indicates that the classification scheme produces meaningful results.

Overall, the classification scheme rendered reliable and plausible results based on the visual validation. Most importantly, claims classified as A or B, i.e., (most) likely surface water floods, are consistently located far away from any watercourse or the topographical location of the claims strongly suggest that these claims were not influenced by a watercourse. Note that the strengths and weaknesses of the classification scheme are elaborated in Sect. 6.

As outlined in Sect. 3.4, we could validate the normalization of the damage data with reference data based on Imhof (2011). The reference data show aggregated number of flood claims per number of insured buildings (Fig. 7a) and the loss per total sum insured (Fig. 7b). The reference data consist of (almost) the complete records of the 14 corresponding
PICBs, whereas our data set contains fewer and fewer records as we move back in time (see Table 3). As we are looking at relative numbers, the comparison is still valid, but the different data coverages have to be kept in mind.

In fact, Fig. 7 highlights that before 1989 the data sets are badly matching but have very similar patterns thereafter. Together with the fact that after 1993 all regions are satisfactorily represented, these are the reasons why we have limited the time series of SWF damage to the period from 1993 to 2013 (see Table 3 and Fig. 14).

The clear bias of the localized claims in comparison to the reference data can mainly be attributed to the $21 \%$ of the claims that could not be localized, i.e., the curves aline much better, when also considering the claims without a precise geocode (Fig. 7). However, a small bias persists, to a larger degree for the number of claims and to a smaller degree for the loss values. The remaining deviations are probably due to the coverage that becomes increasingly different in earlier years and the applied normalization procedure using auxiliary data. Notably, given the simple applied methods, the normalization works exceptionally well.

\subsection{Relevance of surface water flood damage}

Figure 8 reveals that SWFs were responsible for $45 \%$ of all localized flood damage claims between 1999 and 2013 based on the data set D2 that covers $48 \%$ of all Swiss buildings (see Table 3). In terms of loss, however, SWFs only account for $23 \%$ of the total loss. The regional loss shares vary only slightly, i.e., between 15 and $25 \%$, except in the Western Plateau, where SWFs account for $51 \%$ of the total loss. In the same region, SWFs caused two-thirds of all damage claims. In the Jura Mountains, roughly half of all claims could be associated with SWFs. The share is lower in the Eastern Inner Alps and the Eastern Plateau with 43 and 39\%, respectively. 


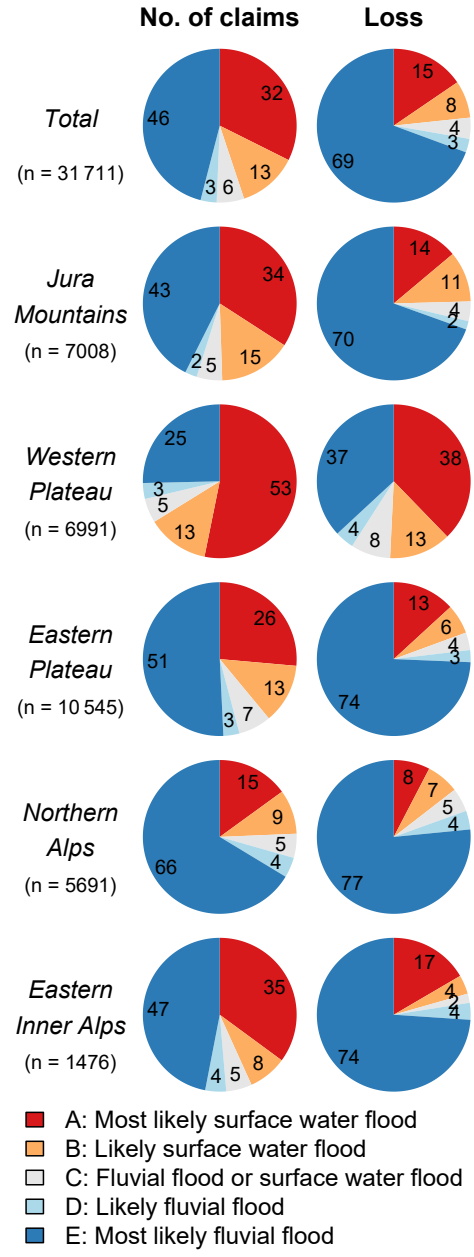

Figure 8. Number of claims and corresponding losses in total and separately for each region. The values stem from the data set D2, which contains seamless claim records of 13 PICBs covering the period of 1999-2013 (see Table 3). The numbers indicate the shares in $\%$, while $n$ represents the sample size.

In the Northern Alps, SWFs are only responsible for $24 \%$ of the flood claims.

The distribution of loss per claim explains why almost half of all claims are only responsible for roughly one-quarter of the total loss. As shown in Fig. 9, the mean loss per SWF claim is considerably lower than the mean loss per claim related to fluvial floods. This is most pronounced when comparing claims of class A (most likely surface water floods) with class $\mathrm{E}$ (most likely fluvial floods): for class A, $95 \%$ of all claims are less or equal to CHF 32 349, while for class E the $95 \%$ percentile is CHF 120330 . Although there is a significant difference, the medians are relatively low for claims of class A and E with values of CHF 3113 and CHF 5554, respectively. Thus, the majority of the claims of all classes are associated with a rather low amount of loss, while the minority of the claims report extreme losses. However, by far the highest losses are associated with claims of class $\mathrm{E}$

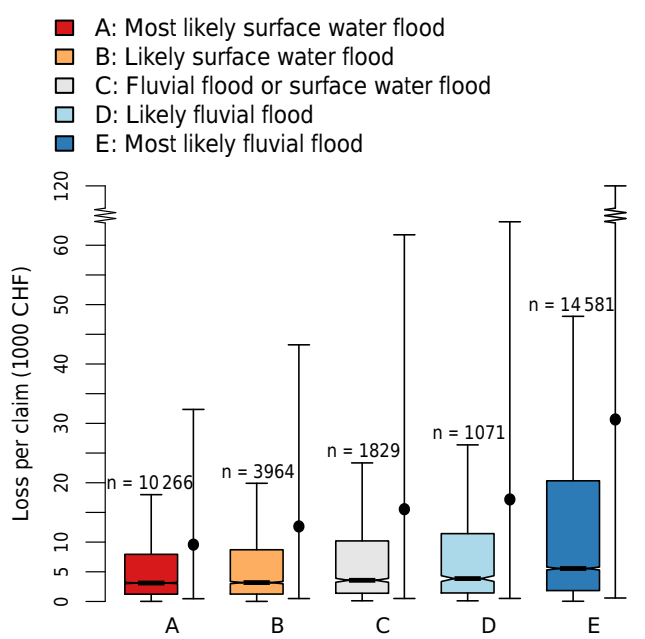

Figure 9. Box plots of losses per claim showing the interquartile range, i.e., the range from the $25 \%$ to the $75 \%$ percentile, and the median (bold horizontal line). Non-overlapping notches indicate significantly differing medians, while the whiskers extent to 1.5 times the interquartile range. Note that the outliers are not plotted. Instead, the 5-95\% percentile range is plotted on the right of each box plot, while the mean value is indicated by the solid dot. Furthermore, note that the $y$ axis is compressed between CHF 60000 and 120000 . The plot is based on the data set D2 (see Table 3).

(see Fig. 9). Grahn and Nyberg (2017) have found similarly skewed distributions caused by pluvial floods in Sweden.

So far, an unanswered question has been how the number of damage claims and associated losses are distributed in relation to the size of the corresponding event. Supposedly, frequent damage associated with low loss values might add up to a substantial sum in the end, as suggested by Kron (2009), for instance. For that matter, we have stratified the data according to the total number of claims per day using five categories ranging from single (1-5 claims per day) to vast ( $>501$ claims per day). We defined an event as a day with at least one claim of any class $(\mathrm{A}-\mathrm{E})$, which amounts to a total of 1490 events in the period of 1999-2013. Obviously, this is a pragmatic definition of an event. Specifically, separate local events occurring at the same day are counted as a single event, while events spanning over several days are counted as individual events. Nevertheless, the pragmatic definition is sufficient for the purpose of a first simple analysis, presented hereafter.

The stratified number of claims (Fig. 10a, total) confirms that smaller events are more frequent than larger events, i.e., 1100 events of the smallest category (single) oppose 11 events of the largest category (vast). Interestingly, days with single and few claims only account for a small share of SWF and fluvial flood claims, although for SWFs the shares are larger. Strikingly, 11 events within the last 15 years with more than 500 claims each account for almost half of the claims caused by fluvial floods but only for one-quarter of the 


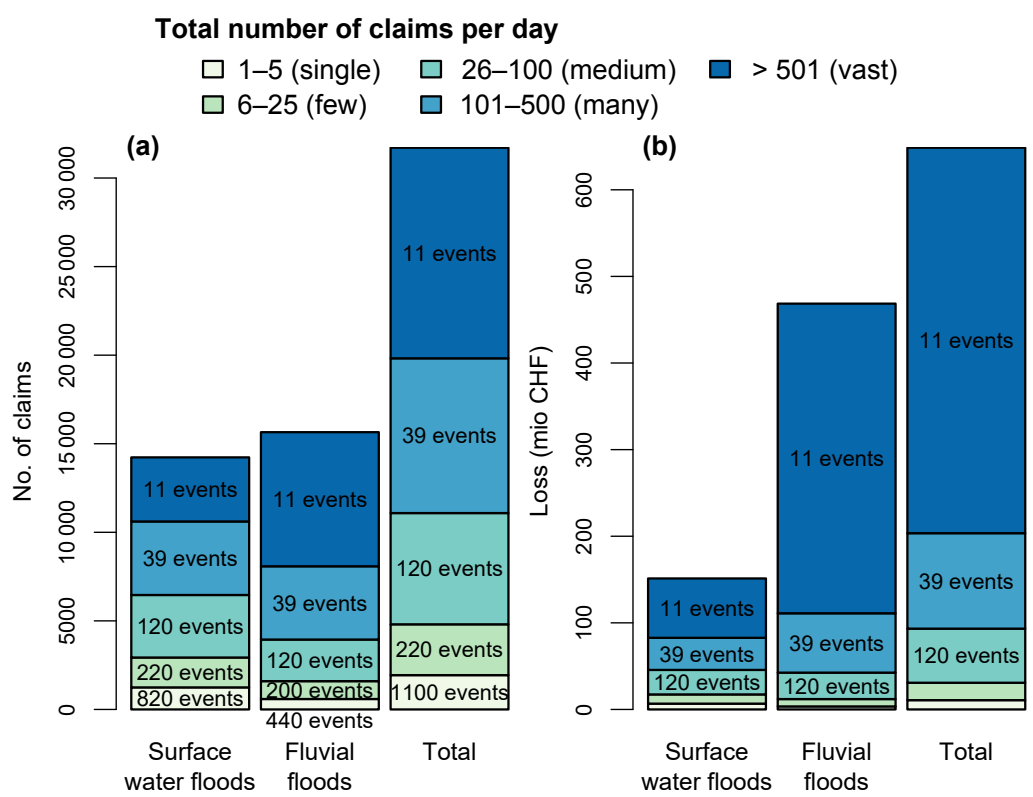

Figure 10. The total number of claims and loss categorized according to the size of the corresponding event, based on the data set D2 (see Table 3). (a) Each claim was categorized according to the total number of flood damage claims that occurred on the same day. For instance, all claims that occurred on 21 June 2007 fall into the category "vast", since 1162 damage claims were registered for that day in total. Thus, all these claims belong to 1 of the 11 largest events within the period of 1999-2013. As each claim was classified (Sect. 3.2), we can further group the data as claims related to SWFs (class A and B) or fluvial floods (class D and E). For the lowest two categories, i.e., single and few, the number of events of SWFs is larger than the number of fluvial flood events. This is due to the fact that some of these events consist of claims categorized as SWFs only. For all other categories, the event numbers match, indicating that for each of these days some of the claims were classified as SWFs while some were classified as fluvial floods. (b) The same stratification is applied to the associated loss. Note that the indication of the number of events for the smallest two event categories, i.e., single and few, were omitted for better readability. However, the values are identical to the values shown in panel (a).

claims associated with SWFs. In contrast, the same 11 events accounted for $45 \%$ of the losses caused by SWFs and even $76 \%$ of the losses caused by fluvial floods (see Fig. 10b). Based on this analysis, we can infer some important characteristics about the damage caused by SWFs:

- SWF damage occurs more frequently during small events, whereas the majority of fluvial flood damage is caused during large events.

- The largest events cause most of the losses, whereas small events only account for insignificant losses in comparison.

Figure 10 has hinted at the fact that each event causes SWF damage alongside fluvial flood damage, except a few of the smallest events. This is further explored by Fig. 11. For each event, i.e., a day with at least one flood damage of any class, the number of claims classified as SWFs is plotted against the number of claims classified as fluvial floods. As expected, most of the events are clustered around the origin, owed to the fact that events with up to five claims account for $74 \%$ (1100) of the total number of events (1490) within the period of 1999-2013.

The most severe floods within the last 15 years in the study domain are highlighted in Fig. 11, which indicates that these flood events are also associated with high numbers of SWF damage, even though these events are mostly known for being devastating fluvial floods. Thus, our analyses show that fluvial flood damage generally coincides with SWF damage. This has been noted before (e.g., Blanc et al., 2012) and can be explained by the fact that both flood types are generated by the same rainfall input. Particularly, during extreme rainfall events, we can expect fluvial flood damages and SWF damage. However, the shares of SWF damage in comparison to fluvial flood damage are different, which might be linked to the type of rainfall. For instance, the damage on 20 21 June 2007 was caused by widespread thunderstorms with local rainfall intensities as high as $73 \mathrm{~mm}^{-1}$ (Hilker et al., 2008) and is associated with a larger share of SWF damage claims (Fig. 11). All other highlighted extreme flood events were triggered by long-duration rainfalls and, at the same time, larger numbers of fluvial flood damage claims. This could be an indication that the type of rainfall, and in particular the rainfall intensity, is an important driver of SWF damage, as noted for instance by Spekkers et al. (2013). 


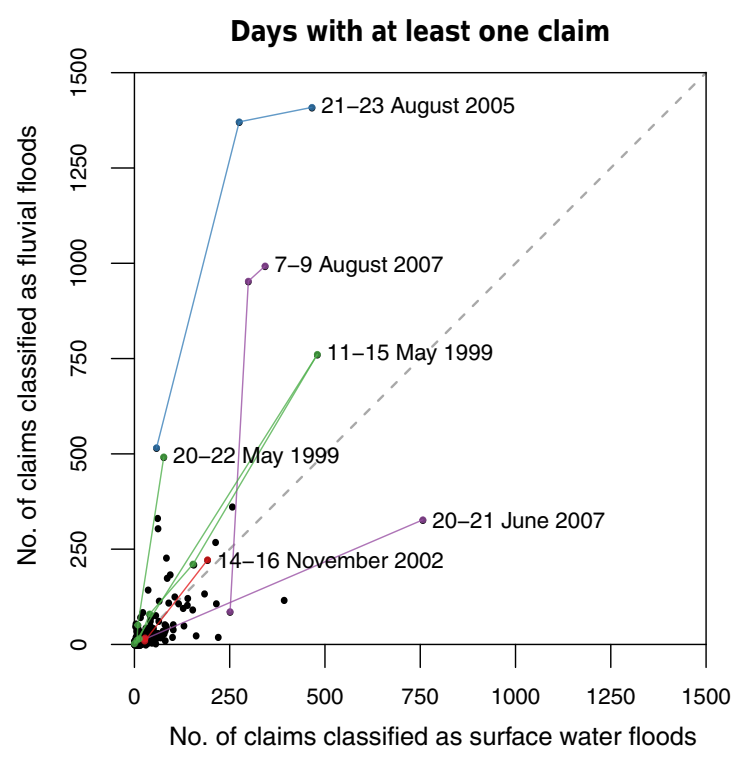

Figure 11. Scatterplot between the number of claims classified as SWFs (class A and B) against claims classified as fluvial floods (class D and E) based on the data set D2 (see Table 3). Each point represents an event, i.e., a day with at least one count of flood damage of any class. Along the dashed gray line, the number of SWF claims and fluvial flood claims is identical. Thus, claims below the line indicate events with more SWF than fluvial flood claims, and events above the line indicate the opposite. The severest flood events within the period of 1999-2013 are highlighted in addition to the event in November 2002, which was the most significant event for the Eastern Inner Alps (see Fig. 13). Moreover, all dates that belong to the same event are connected with lines, and severe events of the same year are shown in the same colors. The event dates are based on Hilker et al. (2008, 2009).

\subsection{Spatial distribution}

Thanks to the spatially explicit input data, we can get a good overview of damage claims triggered by SWFs in space, as shown in Fig. 12. In general, it can be observed that the Swiss Plateau (2 and 3) is exposed most to SWFs, in both relative and absolute terms. Also in the Jura Mountains (1), many buildings are affected by SWFs. In contrast, the alpine regions of Switzerland, i.e., the Northern Alps (4) and also the Eastern Inner Alps (5), are exposed the least.

The visualization of relative values has advantages. For instance, in Bernet et al. (2016), low inundation rates by overland flow were reported for Grisons, i.e., the Eastern Inner Alps, and high values for Fribourg, which lies mostly in the Western Plateau. Figure 12 supports these findings but presents a more differentiated picture, as differences within the mentioned regions can be grasped as well. In particular, we can see that the relative values, i.e., the number of damage claims in relation to the number of buildings within the same raster cell, are not evenly distributed in space. The most affected regions are certainly those with high relative, as well

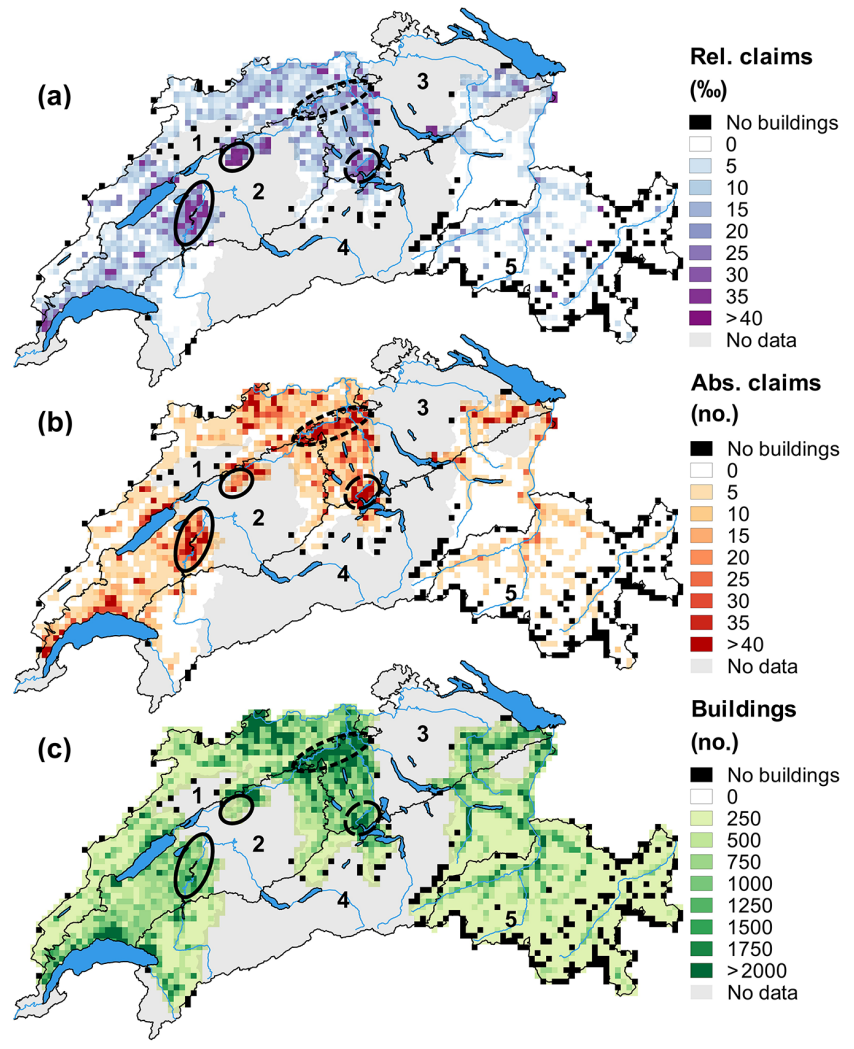

Figure 12. Relative (a) and absolute (b) number of damage claims caused by surface water floods based on the data set D2 covering the period of 1999-2013 (see Table 3), aggregated to regular grids of 3 by $3 \mathrm{~km}$. In addition, the absolute number of buildings per cell is shown (c). The solid ellipses highlight two less populated areas with high relative and absolute number of damage claims. The dashed ellipse indicates a highly populated area with high absolute and relative values, whereas the dotted ellipse marks a densely populated area with high absolute number of damage claims but comparatively low relative values. The numbers indicate the corresponding region: Jura Mountains (1), Western Plateau (2), Eastern Plateau (3), Northern Alps (4) and Eastern Inner Alps (5).

as absolute, numbers of claims, such as the areas indicated by the solid and dashed ellipses in Fig. 12. In addition, we see that such areas do not necessarily coincide with the most densely populated areas (dashed ellipse) but may lie in less populated areas (solid ellipses). Moreover, we can also identify areas that suffer from a high absolute number of damage claims but are exposed less in relative terms (dotted ellipse).

\subsection{Temporal evolution}

To obtain an idea about the distribution of the damage throughout the year, we have plotted the number of claims and associated losses against the month in which they occurred in the form of spider plots (Fig. 13). In relation to SWFs, by far the most damage occurs in the summer months from June to August in all regions except the Eastern Inner 

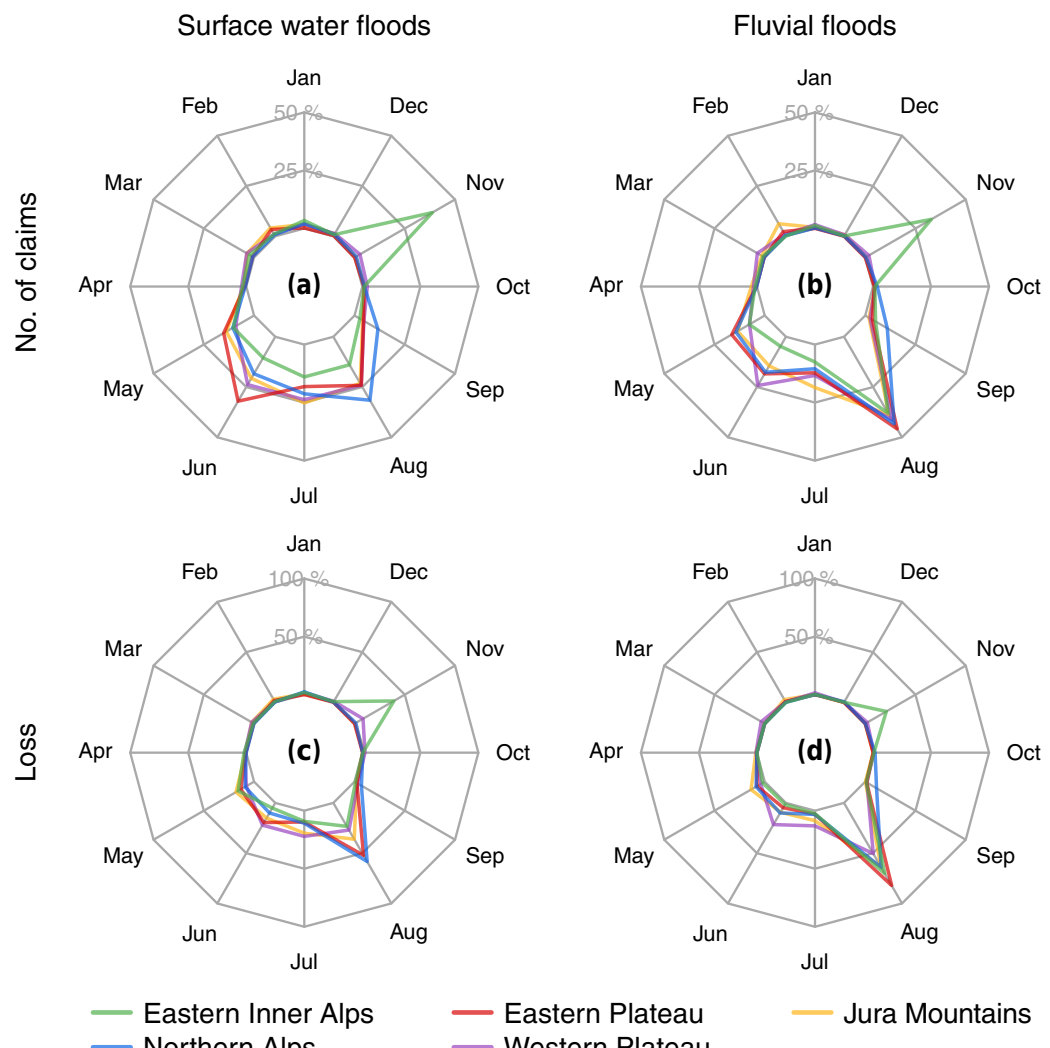

— Eastern Plateau
Western Plateau

- Jura Mountains

- Northern Alps

Figure 13. Spider plots indicating the relative number of damage claims and associated losses for each month. Separate plots are shown for surface water floods (class A and B) and fluvial floods (class D and E). The data set D2 constitutes the underlying data and covers the period from 1999 to 2013 (see Table 3). Note that the scale for the number of claims (a and $\mathbf{b} ; 0-50 \%$ ) is not the same as the scale for the loss (c and $\mathbf{d} ; 0-100 \%)$.

Alps. In this region, the maximum number of damage claims was registered in November, which can be attributed to a single event that occurred on 14-16 November 2002 (Romang et al., 2004), which is highlighted in Fig. 11, as well. The remaining damage claims occurred also mainly in summer, but, due to the devastating event in fall 2002, the values are much lower in comparison to the other regions.

Overall, the number of claims are elevated in the last month in spring, i.e., May, and to a smaller degree in the first month of fall, i.e., September, for most regions. During the rest of the year, i.e., from October to April, very few damage claims are caused, except for the Eastern Inner Alps in November, as discussed before.

Analogous to the number of damage claims, SWFs cause most of the associated losses in the summer months (Fig. 13c). Interestingly, the losses in the Eastern Plateau and the Northern Alps have larger shares in August, compared to the other regions but also compared to the corresponding number of claims (Fig. 13a). This can be explained by the particularly high losses during the August 2005 flooding, as indicated in Fig. 12.

The number of claims and associated losses of fluvial floods is highly concentrated in August in all regions
(Fig. 13b and d). The event in November 2002 that affected the Eastern Inner Alps also shows up prominently for fluvial floods, as elaborated before.

Finally, it is interesting to have a look at the time series of damage caused by SWFs. Based on the normalized values covering the period of 1993-2013, we are able to show the relative number of claims and losses related to SWFs, individually for each region (Fig. 14). The seasonally aggregated values show a distinct pattern. The relative number of claims were almost always highest during the summer, i.e., in June, July and August, which supports the results discussed before. However, there are a few exceptions such as the spring of 1994 and 1999, where corresponding values exceeded the highest values of the same year. Interestingly, in both cases high values were also observed in the following summer, but in other regions. In 2002, a high value in summer that affected the Eastern Plateau was followed by severe damage in the Eastern Inner Alps in November 2002 (Romang et al., 2004), which corresponds to the highest observed value in that region during the whole studied period. High values occurred frequently in the Eastern Plateau but also in the Western Plateau, where in 2007 almost 4\%o of claims per buildings were registered. The highest values in the Jura Moun- 


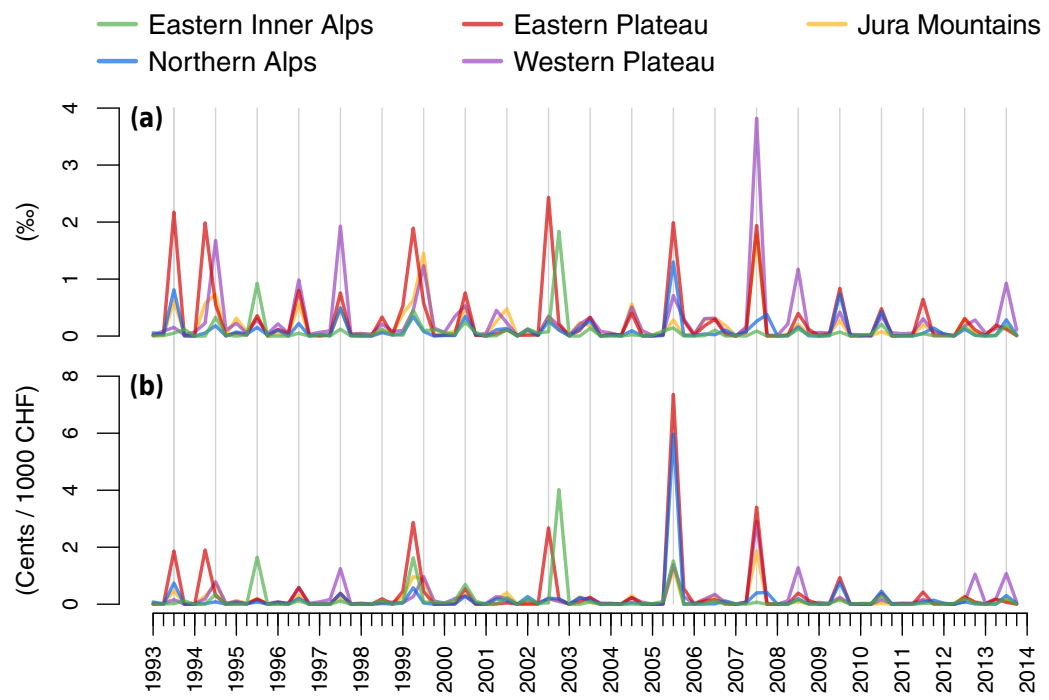

Figure 14. Time series showing the normalized number of SWF damage claims (a), as well as associated loss (b), based on the data set D1 (see Table 3). As pointed out in Sect. 4.1, not all data records cover the whole period; thus the representativeness is decreasing starting from 2003 as we move back to 1993 . Nevertheless, as the aggregated values match well with the reference values (see Fig. 7), and only relative values are considered here, the values are still meaningful.

tains occurred in summer 1999 and 2005. A value higher than $1 \%$ was observed in the Northern Alps only once, namely in 2005.

The values in terms of loss are in line with the claims per buildings, but they are scaled differently. Most pronounced are certainly the high values in the Eastern Plateau and the Northern Alps in 2005. Other high values are observed in spring 1999, summer and fall 2002 and in summer 2007.

Furthermore, the data do not exhibit any trends of SWF damage claims in the period of 1993-2013 based on the seasonal Mann-Kendall test at a significance level of 0.1, except for the Jura Mountains. In that region, the number of claims has been decreasing ( $p=0.006)$. In contrast, the relative losses in the Jura Mountains do not exhibit such a trend $(p=0.52)$. The absence of any increasing trend might be a surprising result, as increasing damage trends are often reported (e.g., Kron et al., 2012; Grahn and Nyberg, 2017). However, it is important to note that in this study we are talking about normalized, relative values, while in the aforementioned publications the trends of the absolute numbers are considered.

\section{Discussions}

The key to the exploitation of the insurance data with regards to SWFs lies in the classification of the damage claims (beside the provision of the data in the first place). The classification scheme, as introduced in this study, is based on the geographical location of each damage with respect to known fluvial flood zones and the hydrological network. On the one hand, this obviously requires spatially explicit dam- age data. On the other hand, it provides a reproducible, objective and, most importantly, an independent classification. These characteristics are important, as the following examples highlight. Grahn and Nyberg (2017) had to exclude damage that occurred on the same day as known fluvial floods in order to distinguish pluvial from fluvial flood claims. However, our results show that fluvial flood damage almost always coincides with damage caused by SWFs. Consequently, excluding damage occurring on the same day as fluvial floods likely introduces a bias. Another example is the statistical model applied by Spekkers et al. (2013) in order to differentiate rainfall-related damage clustered around wet days from non-rainfall-related damage occurring throughout the year. Thereby, the classification of each claim is not independent anymore but depends on how many other damage claims occurred on the same day.

Although the classification scheme presented in this study has striking advantages, it has the following shortcoming: as overland flow propagates over the land surface, it may eventually reach a watercourse (see Fig. 1). Areas alongside watercourses, where the overland flow joins the river, may be a flood hazard zone. If so, all claims in that specific area are classified as a fluvial flood, even though the claim might have been caused by incoming overland flow. However, a more qualified classification entails likely eventspecific, time-consuming manual assessments. In fact, it is extremely difficult to disentangle the different flood types, even more so for events in the more distant past and if no data with that particular focus are available. In contrast, for claims that are located far away of any watercourse, it is very unlikely that they are affected by watercourses at all. 
Therefore, our method renders a lower boundary of claims associated with SWFs, in essence. In reality, the numbers are likely higher, but, as mentioned before, disentangling the flood types within their overlapping domains is difficult.

By applying the classification scheme to the harmonized damage data, we could show that SWFs caused almost the same number of damage claims as fluvial floods. Thereby, our results confirm anecdotal evidence that indicated similar numbers. For instance, one of the few quantitative studies about SWFs in Switzerland reported that at least half of the flood damage claims in the canton of Aargau were caused by overland flow (Aller and Petrascheck, 2008). However, the study is comprehensible in terms of neither the applied methods nor the underlying data and covers only a small part of Switzerland. Thus, for the first time, we can present sound evidence about the relevance of SWFs in Switzerland based on a large data set including more than 30000 damage claims covering 15 years and $48 \%$ of all Swiss buildings.

Despite the remarkably high number of damage claims caused by SWFs, our results show that SWFs only account for roughly one-quarter of the total loss, which is in line with results from the pilot study (i.e., Bernet et al., 2016). Nevertheless, the associated yearly loss is highly significant, as the following numbers exemplify: the median of total yearly losses to buildings caused by fluvial floods within the considered regions is even slightly lower (5.0 mio CHF yr ${ }^{-1}$ ) than the median of SWF losses (5.9 mio CHF yr ${ }^{-1}$ ) based on the data set D2 covering the period of 1999-2013 (see Table 3). However, the mean yearly loss of fluvial floods is more than 3 times the loss caused by SWFs (i.e., 31.3 mio CHF $\mathrm{yr}^{-1}$ versus $10.1 \mathrm{mioCHF} \mathrm{yr}^{-1}$, respectively). The difference between the maximum yearly losses caused by each flood type is even more pronounced: while the maximum loss of SWFs amounts to 38.3 mio CHF yr$^{-1}$ in 2005 , fluvial floods caused 234.3 mio CHF yr $^{-1}$ in the same year, which corresponds to a factor of roughly 6 .

These observation concerning annual flood losses are supported by the characteristics of the individual losses. Their exploration (Fig. 9) expressed that the range of loss per claim is much narrower for SWFs than for fluvial floods. As SWFs are expected to be associated with significantly lower flow depth than fluvial floods, this might be one of the main reasons for the lower associated loss, since water depth is among the most significant single impact parameters for structural damage to residential buildings (e.g., Kreibich et al., 2009; Merz et al., 2013). Interestingly, the median loss of each claim associated with fluvial floods is also rather low, although significantly higher than the median loss of claims related to SWF. However, the highest losses per claim are caused by fluvial floods during the most severe events within the study domain (Fig. 10). As during extreme events, larger areas are affected and the associated shares of objects inundated by large water depths are higher (Elmer et al., 2010), higher losses per claim can be expected. Along the same lines, Hilker et al. (2009) report that the most severe events contribute to more than half of the estimated total loss and Barredo (2009) found an even higher share for flood losses in the whole of Europe. Undoubtedly, loss ratios are higher during more extreme events (Elmer et al., 2010). Although this probably also holds true for damage caused by SWFs, such damage certainly seems less influenced by the severity of the event (see Figs. 9 and 10). Consequently, SWFs may rarely cause the total destruction of a building, and associated loss ratios may, thus, mostly be well below 1 .

As outlined in the introduction, this study is limited to direct tangible loss to buildings. Therefore, the absolute loss values are low in comparison to other loss estimations that include other losses, as well. For instance, Hilker et al. (2009) report a mean financial loss of 317.2 mio CHF yr $^{-1}$ between 1972 and 2007, which is roughly 7 times higher than the mean of all flood losses to buildings, as represented by our data set. For one, the data published by Hilker et al. (2009) cover the whole of Switzerland and consider a longer period. More importantly, however, these estimates also include damage to infrastructure, forestry and agricultural land, in addition to damage to buildings and their content. Therefore, the associated losses are inherently higher than the numbers presented in this study. This exemplifies that one has to be careful when comparing values from different data sources (Kron et al., 2012). Moreover, it highlights the fact that damage to buildings are associated with just a small fraction of the total loss caused by SWFs for the society. Nevertheless, these data serve well for assessing the relevance of SWF damage in Switzerland, especially when considering relative values.

The spatial distribution of damage caused by SWFs can be deceiving: obviously, an area with a higher building density will likely result in a larger number of damage claims compared to an area that is less populated (Fig. 12b versus c). Therefore, it is important to have a look at relative values, as well (Fig. 12a). Thereby, the effect of higher values caused by a denser number of buildings is considered. However, the relative values are quite sensitive in sparsely populated areas. A damaged house with virtually no other houses in the vicinity will produce a high relative value or a low value if the same is not affected. In contrast, in more populated areas, the relative value will not change much in case a building is more or less damaged. Thus, to obtain a complete picture, the relative and absolute values should be considered alongside the building density. In that way, the most exposed areas can be identified, like the two highlighted areas in the Western Plateau that are associated with high relative and absolute numbers of damage claims (Fig. 12).

Furthermore, it is important to keep in mind that in case an area has no registered damage, it does not necessarily mean that the area has not been affected by a floods at all. It just indicates that either no buildings were in the vicinity of the flooded area or the buildings were properly protected against such floods. Therefore, damage records can only indicate floods that lead to some sort of damage and never to the 
occurrence of floods in the hydrological sense, as discussed in the introduction (see Fig. 1). However, understanding the characteristics of damaging floods can open the stage to understand the process in a broader context, as well.

The temporal distribution of claims related to SWFs exhibits a distinct seasonality (Figs. 13 and 14). Similar to the flood losses reported by Hilker et al. (2009), most damage clearly occurs in summer, with a few exceptions. Therefore, thunderstorms associated with short but intense rainfall are certainly an important driver of SWF damage. Nevertheless, long duration rainfall events are also responsible for a large share of SWF damage claims, highlighted by the most severe events that are mostly associated with long duration precipitation. In contrast, much fewer damage claims are caused in spring and fall, and virtually no damage claims are caused in winter. Damage to buildings in winter can likely be attributed to rather local events coinciding with conditions promoting overland flow generation such as rain on frozen soils. Overall, these observations have important implications for assessing the hazard of SWFs. In particular, simply focusing on high-intensity rainfall events may lead to an underestimation of the risk of SWFs.

Although the time series is relatively short, the data do not exhibit any increasing trends of SWF damage in the period of 1993-2013. Obviously, the general increase of absolute loss in time, which can be found in our data as well, is eliminated when the data are normalized. Thus, as suggested for instance by Kundzewicz et al. (2014), the increase in loss can be mainly attributed to the socioeconomic development. However, we did not consider further aspects that could have an influence on such trends, such as a change in vulnerability (Bouwer, 2011). Moreover, insurance or local governmental policies that might have changed over time were not taken into account either. Nevertheless, it is important to note that increasing absolute losses are most likely attributable not to climate change but to socioeconomic factors (e.g., Cutter and Emrich, 2005; Barredo, 2009; Bouwer, 2011; Kundzewicz et al., 2014). Consequently, the major associated risks related to SWF damage is not climate change but the increased exposure due to population growth and increasing wealth. This has implications for decision and policy makers, as well as for insurance companies and similar stakeholders.

Indeed, the flood processes are a complex interlinked system, as Evans et al. (2004) stated. In fact, the insurance data illustrated that damage caused by SWFs occur (almost) always alongside claims caused by fluvial floods (see Fig. 11). $\mathrm{Be}$ it a short and intense thunderstorm or a long duration event, rainfall is the main trigger of every SWF and (almost) every fluvial flood. Understandably, if there is enough rainfall to cause a SWF, it may as well cause or at least contribute to a fluvial flood once part of the water reaches the next watercourse. Undoubtedly, severe events that include hundreds or thousands of damage claims entail a combination of flood processes, while, of course, some local events may be associated with a single flood process only.

\section{Conclusions}

In this study, we have presented a simple and pragmatic approach of how spatially explicit insurance data records can be exploited to investigate damage caused by SWFs. The method provides a robust lower estimate of SWF damage. Using the presented percentile values (Table 4), the method is applicable for classifying any claim in Switzerland except in the Western Inner Alps and Southern Alps, where data were lacking. For these regions, appropriate values could be approximated. Moreover, the method is transferable to other regions and countries but has to be adapted to locally available flood hazard maps.

There seems to be a consensus among practitioners and experts that SWFs are responsible for a large share of all flood damage. However, this perception stems not from quantitative research but rather from single case studies or practical experience and, thus, lacks evidence. With the study at hand, we are able to quantify the striking relevance of SWFs in Switzerland based on a sound data basis, regionally representing $39-100 \%$ of all buildings over a period of 15 years. The data reveal that SWFs cause nearly as many damage claims as fluvial floods. In contrast, SWFs account for roughly one-quarter of the direct tangible losses, driven by lower losses per SWF claim. This hints at the different processes' characteristics with generally low flow depths associated with SWFs, opposed to both low and high, static and dynamic, flow depths during fluvial floods that are additionally sensitive to the severity of an event.

The most affected areas are clearly the Western Plateau, in both relative and absolute terms, followed by the Eastern Plateau and the Jura Mountains. The more mountainous regions, i.e., the Northern Alps and the Eastern Inner Alps, are affected less. Notably, there are also large differences between the spatial distribution of damage within each region. By relating the absolute number of damage claims to the number of buildings in the vicinity, the effect of varying building densities can be considered. Nevertheless, in sparsely populated areas the relative numbers are sensitive and, thus, less robust due to the particularly low building densities. Furthermore, not all regions are affected by SWFs to the same extent throughout the year. However, in all regions most of the damage occurs in summer, save a few exceptions.

In general, the spatial and temporal distribution of SWF damage is complex. Different factors might be responsible for high damage within certain areas or during certain periods. For instance, the meteorological forcing differ spatially and temporally, the predisposition due to unfavorable soils or land use practices play a role, past human interventions such as the installation of drainage and the removal of small natural rivulets can have an influence, but also slightly differing practices by the insurance companies or different rules applied for buildings to be built might be relevant. Undoubtedly, we stand at the beginning of better understanding SWFs in Switzerland and also on an international level. Meanwhile, 
a common terminology is the base to strengthening and extending the science within this field across the countries' borders.

This study highlights the fact that SWFs are a highly significant flood process in Switzerland. Unlike for fluvial flood hazards, there is no publicly available up-to-date information about the hazard of SWFs, in spite of the process's obvious relevance. Since SWFs can occur practically anywhere in the landscape, it is paramount to have detailed information about local SWF hazards. Such information can help to make wellfounded decisions by all different stakeholders, e.g., planning and installing appropriate property protections by house owners, applying measures to reduce overland flow generation on agricultural fields by local farmers, providing surface retention ponds by municipalities or amending regulations to prevent SWF damage by the federal government. However, as a first priority, SWFs in general and the influencing factors of SWFs in particular should be further studied and, ultimately, better understood.
As a first step in this direction, we propose that SWFs should not be regarded as an isolated process by itself. A better way is probably to extend our focus from rivers and lakes alone to hidden rivulets, covered drains, the sewer system, impervious areas, agricultural fields and headwaters, which all contribute to the generation of SWFs. Therefore, we should regard overland flow and ponding as an integrated part of our catchments. In this manner we may start to understand the complex interlinked flood processes better in the future.

Data availability. The data, on which this study is based, were provided by 15 different insurance companies. Each record contains confidential information such as the location (address and/or coordinates), claim date and associated loss. Due to privacy protection, the data are subjected to strict confidentiality and, thus, cannot be made accessible. 


\section{Appendix A: Normalization}

Obviously, it would be best to normalize the damage data with the corresponding property data of the respective insurance company. However, property data are generally even more difficult to obtain than damage data, as the former contain additional sensitive and confidential information. Therefore, ancillary data are required to estimate the number of insured buildings and the replacement value of each corresponding building. Moreover, as these values change over time, we need additional ancillary data to take these temporal changes into account. As outlined in Sect. 3.3, the spatial normalization and the temporal normalization of the damage data are described in detail in the following sections.

After all, we divide the number of claims by the estimated number of insured buildings, while the losses are divided by the corresponding total sum insured. For that matter, all quantities have to be spatially aggregated. For this study, we aggregated the data to regular grids and visually compared the corresponding maps. Fine resolutions produced patchy patterns, while local characteristics got lost with coarse resolutions. Thus, we chose a resolution of 3 by $3 \mathrm{~km}$, which constitutes a balanced compromise between level of detail and smoothing. The point of origin of the corresponding rasters is chosen arbitrarily. We acknowledge that the choice may change the absolute values of each cell but in general does not change the larger picture.

\section{A1 Spatial normalization}

As property data were not available, we inferred the number of buildings using ancillary data. For this purpose, we made use of the terrain model swissTLM3D (Table 2). From this data set, the number of buildings represented by their footprints can easily be extracted. However, the data needed to be preprocessed: invalid geometries had to be corrected and overlapping polygons were dissolved into single polygons in order to obtain a homogeneous data set as of 2013.

The definitions of a building are quite similar among the PICBs (Imhof, 2011). Nevertheless, the number of footprints does not match the number of insured buildings, since a row house might be represented by one footprint, while it constitutes several buildings as defined by the respective insurance company, for instance. To consider this, we referred to publicly available annual reports of 2013 and, thereby, obtained the total number of insured buildings for each PICB. We then divided the obtained values by the number of footprints, resulting in a simple multiplication factor $\left(f_{n}\right.$, Table A1). By multiplying the aggregated number of buildings with the factor $f_{n}$, we obtain the approximated number of insured buildings as of 2013. For each grid cell, the aggregated number of claims is then divided by the aggregated number of buildings to obtain spatially normalized damage numbers.

To normalize the loss, we need to relate the loss values to the total sum insured. There are few published methodolo- gies to assess building values in detail, but these can be too time-consuming for applications in large study areas (Kleist et al., 2006). Given the large data set, we chose a simple approach similar to the method shown by Grünthal et al. (2006), who used the product of mean insurance values and the number of buildings to estimate the replacement costs of residential buildings. However, instead of the buildings' footprint area, we considered the buildings' volume, which we expect to be a more representative measure for estimating building values.

Specifically, we first assessed the mean altitude of each building's footprint by using common zonal statistic functions of a GIS and a DEM as input (Table 2). The top of each building was then assessed by the same method but using a digital surface model instead. The approximated building height resulted from the difference of the two values. Implausible results were corrected; i.e., values below $3.5 \mathrm{~m}$ or above $100 \mathrm{~m}$ were set to the standard building height of $3.5 \mathrm{~m}$. Thus, a standard height of $3.5 \mathrm{~m}$ is assigned for buildings that might have been built after the last update of the digital surface model in 2008 (see Table 2). Then, the building volumes are obtained by multiplying the building's footprint area with the mean building height. The total building volume for each canton is assessed and divided by the respective total sum insured in order to obtain the insurance value per cubic meter $\left(\rho_{\mathrm{v}}\right.$, Table A1). The product of each building's volume and $\rho_{\mathrm{v}}$ finally results in each building's value as of 2013. Analogous to the number of buildings, the loss is aggregated to regular grids and divided by the aggregated sum insured.

\section{A2 Temporal normalization}

As the considered terrain model itself does not include attributes for such considerations, we used another auxiliary data set, i.e the buildings and dwellings statistic of the Swiss Federal Statistical Office as of 2013 (see Table 2), from which the number of newly built residential buildings can be inferred. The data are regularly updated, whereas the number of residential buildings can be assessed at any time by linear interpolation between the sampling points. Normalizing with the number of buildings per canton as of 2013 (Appendix A1), we obtain a dimensionless factor $\left(f_{t}\right.$, Table A2). With the assumption that the residential buildings are representative for the development of all buildings, we obtain the temporal development of the number of buildings and the total sum insured. To that end, we multiply the interpolated factor $f_{t}$ for each time step with the number of buildings and the total sum insured as per 2013. 
Table A1. Factors used for the data normalization, i.e., the dimensionless multiplication factor $\left(f_{n}\right)$ relating the number of building footprints to the number of buildings as defined by each PICB, as well as the estimated insurance value per cubic meter $\left(\rho_{\mathrm{V}}\right)$. For the derivation of these factors, the number of buildings and the total sum insured was required for each PICB. The corresponding values are generally published in the publicly available annual reports. Specifically, the values from the year 2013 were extracted for the PICB of the cantons of Aargau (AG), Basel-Landschaft (BL), Basel-Stadt (BS), Fribourg (FR), Grisons (GR), Jura (JU), Neuchâtel (NE), St Gall (SG), Solothurn (SO), Vaud (VD) and Zug (ZG). The values for the PICB of Glarus (GL) and Nidwalden (NW) were not reported, so that the mean value of 1.37 was adopted for the multiplication factor $f_{n}$ and the total sum insured was inferred indirectly from the respective annual reports.

\begin{tabular}{|c|c|c|c|c|c|c|c|c|c|c|c|c|c|c|}
\hline & AG & BL & $\mathrm{BS}$ & FR & GL & GR & JU & $\mathrm{LU}$ & $\mathrm{NE}$ & NW & SG & $\mathrm{SO}$ & VD & $\mathrm{ZG}$ \\
\hline$f_{n}(-)$ & 1.34 & 1.56 & 3.92 & 1.30 & 1.37 & 1.46 & 1.18 & 1.27 & 1.28 & 1.37 & 1.25 & 1.33 & 1.33 & 1.28 \\
\hline$\rho_{\mathrm{V}}\left(\mathrm{CHF} \mathrm{m}^{-3}\right)$ & 720 & 734 & 1056 & 577 & 582 & 868 & 449 & 575 & 656 & 706 & 628 & 664 & 733 & 1029 \\
\hline
\end{tabular}

Table A2. Multiplicative factors $\left(f_{t}\right)$ indicating the number of buildings in relation to the total number of buildings as of 2013. In this table, the factors' values are shown at the sampling points of the building and dwelling statistics, provided by the Swiss Federal Statistical Office (see Table 2).

\begin{tabular}{rrrrrrrrrrrrrrrr}
\hline Year & AG & BL & BS & FR & GL & GR & JU & LU & NE & NW & SG & SO & VD & ZG \\
\hline 1980 & 0.58 & 0.63 & 0.91 & 0.53 & 0.78 & 0.66 & 0.70 & 0.56 & 0.74 & 0.61 & 0.65 & 0.63 & 0.67 & 0.55 \\
1985 & 0.64 & 0.69 & 0.93 & 0.59 & 0.81 & 0.71 & 0.74 & 0.63 & 0.78 & 0.68 & 0.70 & 0.69 & 0.72 & 0.62 \\
1990 & 0.72 & 0.76 & 0.94 & 0.67 & 0.86 & 0.79 & 0.80 & 0.70 & 0.84 & 0.75 & 0.77 & 0.76 & 0.79 & 0.70 \\
1995 & 0.78 & 0.81 & 0.96 & 0.73 & 0.90 & 0.84 & 0.85 & 0.77 & 0.87 & 0.80 & 0.82 & 0.82 & 0.82 & 0.76 \\
2000 & 0.85 & 0.88 & 0.97 & 0.80 & 0.94 & 0.89 & 0.89 & 0.84 & 0.91 & 0.86 & 0.88 & 0.88 & 0.86 & 0.84 \\
2005 & 0.91 & 0.93 & 0.99 & 0.87 & 0.96 & 0.93 & 0.93 & 0.90 & 0.94 & 0.92 & 0.92 & 0.93 & 0.91 & 0.91 \\
2010 & 0.97 & 0.98 & 1.00 & 0.95 & 0.99 & 0.97 & 0.98 & 0.96 & 0.98 & 0.97 & 0.97 & 0.97 & 0.97 & 0.97 \\
2013 & 1.00 & 1.00 & 1.00 & 1.00 & 1.00 & 1.00 & 1.00 & 1.00 & 1.00 & 1.00 & 1.00 & 1.00 & 1.00 & 1.00 \\
\hline
\end{tabular}


Competing interests. The authors declare that they have no conflict of interest.

Special issue statement. This article is part of the special issue "Damage of natural hazards: assessment and mitigation". It is not associated with a conference.

Acknowledgements. Funding from the Swiss Mobiliar supported the completion of this research. We thank the Swiss Mobiliar in general and the natural hazards group in particular for acquiring and compiling the flood hazard maps and providing claim records. Furthermore, we would like to thank the public insurance companies for buildings of the cantons Aargau, Basel-Landschaft, Basel-Stadt, Fribourg, Glarus, Grisons, Jura, Lucerne, Neuchâtel, Nidwalden, St Gall, Solothurn, Vaud and Zug for providing claim records and supporting us during the data harmonization process. Also, we would like to thank the Federal Office of Topography for providing the corresponding spatial data and the canton of Lucerne for providing the overland flow map. Last but not least, we thank Markus Mosimann for his support harmonizing the insurance data, Veronika Röhlisberger for the joint effort to collect and harmonize the insurance data in the first place, in addition to her support for the estimation of the buildings' values, and, generally, we thank her and Andreas Zischg for the many valuable inputs.

Edited by: Daniela Molinari

Reviewed by: two anonymous referees

\section{References}

Aller, D. and Petrascheck, A.: Schadensentwicklung im Kanton Aargau, in: Ereignisanalyse Hochwasser 2005, Teil 2-Analyse von Prozessen, Massnahmen und Gefahrengrundlagen, edited by: Bezzola, G. R. and Hegg, C., Umwelt-Wissen Nr. 0825, 82-92, Bundesamt für Umwelt (BAFU) and Eidgenössische Forschungsanstalt für Wald Schnee und Landschaft (WSL), Bern, Switzerland, 2008.

Andrieu, H., Browne, O., and Laplace, D.: Les crues en zone urbaine: des crues éclairs?, La Houille Blanche, 2, 89-95, https://doi.org/10.1051/lhb:200402010, 2004.

Barredo, J. I.: Normalised flood losses in Europe: 1970 2006, Nat. Hazards Earth Syst. Sci., 9, 97-104, https://doi.org/10.5194/nhess-9-97-2009, 2009.

Bernet, D. B., Weingartner, R., and Prasuhn, V.: Exploiting damage claim records of public insurance companies for buildings to increase knowledge about the occurrence of overland flow in Switzerland, in: INTERPRAEVENT 2016 - Conference Proceedings, edited by: Koboltschnig, G., 221-230, International Research Society INTERPRAEVENT, 2016.

Blanc, J., Hall, J. W., Roche, N., Dawson, R. J., Cesses, Y., Burton, A., and Kilsby, C. G.: Enhanced efficiency of pluvial flood risk estimation in urban areas using spatial-temporal rainfall simulations, J. Flood Risk Manage., 5, 143-152, https://doi.org/10.1111/j.1753-318X.2012.01135.x, 2012.

Boardman, J.: A short history of muddy floods, Land Degrad. Dev., 21, 303-309, https://doi.org/10.1002/ldr.1007, 2010.
Bouwer, L. M.: Have disaster losses increased due to anthropogenic climate change?, B. Am. Meteorol. Soc., 92, 39-46, https://doi.org/10.1175/2010BAMS3092.1, 2011.

Brutsaert, W.: Hydrology: An introduction, Cambridge University Press, Cambridge and New York, 2005.

Castro, D., Einfalt, T., Frerichs, S., Friedeheim, K., Hatzfeld, F., Kubik, A., Mittelstädt, R., Müller, M., Seltmann, J., and Wagner, A.: Vorhersage und Management von Sturzfluten in urbanen Gebieten (URBAS): Schlussbericht des vom Bundesministerium für Bildung und Forschung geförderten Vorhabens, Hydrotec GmbH and Fachhochschule Aachen and Deutscher Wetterdienst, Aachen, Germany, available at: http://www.urbanesturzfluten.de (last access: 21 September 2017), 2008.

CEPRI: Gérer les inondations par ruissellement pluvial: Guide de sensibilisation, Centre Européen de Prévention du Risque d'Inondation, Orléans, France, available at: http://www.cepri.net/ Ruissellement_pluvial.html (last access: 21 September 2017), 2014.

Cheng, C. S., Li, Q., Li, G., and Auld, H.: Climate change and heavy rainfall-related water damage insurance claims and losses in Ontario, Canada, J. Water Resource Prot., 4, 49-62, https://doi.org/10.4236/jwarp.2012.42007, 2012.

Chow, V. T., Maidment, D. R., and Mays, L. W.: Applied hydrology, McGraw-Hill series in water resources and environmental engineering, McGraw-Hill, New York, 1988.

Coulthard, T. J. and Frostick, L. E.: The Hull floods of 2007: implications for the governance and management of urban drainage systems, J. Flood Risk Manage., 3, 223-231, https://doi.org/10.1111/j.1753-318X.2010.01072.x, 2010.

Cutter, S. L. and Emrich, C.: Are natural hazards and disaster losses in the U.S. increasing?, EOS T. Am. Geophys. Un., 86, 381-389, https://doi.org/10.1029/2005EO410001, 2005.

Davy, L.: La catastrophe nîmoise du 3 Octobre 1988: était-elle previsible?, Bull. Soc. Languedoc. Geogr., 24, 133-162, 1990.

de Moel, H., van Alphen, J., and Aerts, J. C. J. H.: Flood maps in Europe - methods, availability and use, Nat. Hazards Earth Syst. Sci., 9, 289-301, https://doi.org/10.5194/nhess-9289-2009, 2009.

Douglas, I., Garvin, S., Lawson, N., Richards, J., Tippett, J., and White, I.: Urban pluvial flooding: a qualitative case study of cause, effect and nonstructural mitigation, J. Flood Risk Manage., 3, 112-125, https://doi.org/10.1111/j.1753318X.2010.01061.x, 2010.

Douguédroit, A.: Précipitations extrêmes et "crues urbaines" à Marseille (France) de 1861 à 2007, Bulletin de la Société géographique de Liège, 51, 105-114, 2008.

DWA: Starkregen und urbane Sturzfluten - Praxisleitfaden zur Überflutungsvorsorge, Vol. T1/2013 of DWA-Themen, Deutsche Vereinigung für Wasserwirtschaft, Abwasser und Abfall (DWA), Hennef, Germany, 2013.

Egli, T.: Wegleitung Objektschutz gegen meteorologische Naturgefahren, Vereinigung Kantonaler Feuerversicherungen, Bern, Switzerland, available at: http://vkf.ch/VKF/Downloads (last access: 21 September 2017), 2007.

Elmer, F., Thieken, A. H., Pech, I., and Kreibich, H.: Influence of flood frequency on residential building losses, Nat. Hazards Earth Syst. Sci., 10, 2145-2159, https://doi.org/10.5194/nhess10-2145-2010, 2010. 
Evans, E., Ashley, R., Hall, J., Penning-Roswell, E., Saul, A., Sayers, P., Thorne, C., and Watkinson, A.: Foresight: future flooding scientific summary: Volume 1 - future risks and their drivers, Office of Science and Technology, London, UK, available at: https: //www.gov.uk/government/publications/future-flooding (last access: 21 September 2017), 2004.

Evrard, O., Bielders, C. L., Vandaele, K., and van Wesemael, B.: Spatial and temporal variation of muddy floods in central Belgium, off-site impacts and potential control measures, Catena, 70, 443-454, https://doi.org/10.1016/j.catena.2006.11.011, 2007

Falconer, R. H., Cobby, D., Smyth, P., Astle, G., Dent, J., and Golding, B.: Pluvial flooding: new approaches in flood warning, mapping and risk management, J. Flood Risk Manage., 2, 198-208, https://doi.org/10.1111/j.1753-318X.2009.01034.x, 2009.

Field, C. B., Barros, V., Stocker, T. F., Quin, D., Dokken, D. J., Ebi, K. L., Mastrandrea, M. D., Mach, K. J., Plattner, G.-K., and Allen, S. K. (Eds.): Managing the risks of extreme events and disasters to advance climate change adaption: A special report of working groups I and II of the Intergovernmental Panel on Climate Change, Cambridge University Press, Cambridge, UK and New York, USA, 2012.

Fiener, P., Auerswald, K., Winter, F., and Disse, M.: Statistical analysis and modelling of surface runoff from arable fields in central Europe, Hydrol. Earth Syst. Sci., 17, 4121-4132, https://doi.org/10.5194/hess-17-4121-2013, 2013.

Gaitan, S., van de Giesen, N. C., and ten Veldhuis, J. A. E.: Can urban pluvial flooding be predicted by open spatial data and weather data?, Environ. Modell. Softw., 85, 156-171, https://doi.org/10.1016/j.envsoft.2016.08.007, 2016.

Gall, M., Borden, K. A., and Cutter, S. L.: When do losses count? Six fallacies of natural hazards loss data, B. Am. Meteorol. Soc., 90, 799-809, https://doi.org/10.1175/2008BAMS2721.1, 2009.

Gaume, E., Bain, V., Bernardara, P., Newinger, O., Barbuc, M., Bateman, A., Blaškovičová, L., Blöschl, G., Borga, M., Dumitrescu, A., Daliakopoulos, I., Garcia, J., Irimescu, A., Kohnova, S., Koutroulis, A., Marchi, L., Matreata, S., Medina, V., Preciso, E., Sempere-Torres, D., Stancalie, G., Szolgay, J., Tsanis, I., Velasco, D., and Viglione, A.: A compilation of data on European flash floods, J. Hydrol., 367, 70-78, https://doi.org/10.1016/j.jhydrol.2008.12.028, 2009.

Gourley, J. J., Hong, Y., Flamig, Z. L., Arthur, A., Clark, R., Calianno, M., Ruin, I., Ortel, T., Wieczorek, M. E., Kirstetter, P.-E., Clark, E., and Krajewski, W. F.: A Unified Flash Flood Database across the United States, B. Am. Meteorol. Soc., 94, 799-805, https://doi.org/10.1175/BAMS-D-12-00198.1, 2013.

Grahn, T. and Nyberg, L.: Assessment of pluvial flood exposure and vulnerability of residential areas, International Journal of Disaster Risk Reduction, 21, 367-375, https://doi.org/10.1016/j.ijdrr.2017.01.016, 2017.

Grosjean, G.: Die Schweiz: Der Naturraum in seiner Funktion für Kultur und Wirtschaft, Vol. U1 of Geographica Bernensia, Arbeitsgemeinschaft Geographica Bernensia, Bern, 1975.

Grünewald, U.: Erkenntnisse und Konsequenzen aus dem Sturzflutereignis in Dortmund im Juli 2008, KW-Korrespondenz Wasserwirtschaft, 8, 422-428, https://doi.org/10.3243/kwe2009.08.003, 2009.

Grünthal, G., Thieken, A. H., Schwarz, J., Radtke, K. S., Smolka, A., and Merz, B.: Comparative risk assessments for the city of
Cologne - storms, floods, earthquakes, Nat. Hazards, 38, 21-44, https://doi.org/10.1007/s11069-005-8598-0, 2006.

Haghighatafshar, S., la Cour Jansen, Jes, Aspegren, H., Lidström, V., Mattsson, A., and Jönsson, K.: Storm-water management in Malmö and Copenhagen with regard to climate change scenarios, Vatten, 70, 159-168, 2014

Hankin, B., Waller, S., Astle, G., and Kellagher, R.: Mapping space for water: screening for urban flash flooding, J. Flood Risk Manage., 1, 13-22, https://doi.org/10.1111/j.1753318X.2008.00003.x, 2008.

Hilker, N., Badoux, A., and Hegg, C.: Unwetterschäden in der Schweiz im Jahre 2007, Wasser Energie Luft, 100, 115-123, 2008.

Hilker, N., Badoux, A., and Hegg, C.: The Swiss flood and landslide damage database 1972-2007, Nat. Hazards Earth Syst. Sci., 9, 913-925, https://doi.org/10.5194/nhess-9-913-2009, 2009.

Hirsch, R. M., Slack, J. R., and Smith, R. A.: Techniques of trend analysis for monthly water quality data, Water Resour. Res., 18, 107-121, https://doi.org/10.1029/WR018i001p00107, 1982.

Hurford, A. P., Parker, D. J., Priest, S. J., and Lumbroso, D. M.: Validating the return period of rainfall thresholds used for Extreme Rainfall Alerts by linking rainfall intensities with observed surface water flood events, J. Flood Risk Manage., 5, 134-142, https://doi.org/10.1111/j.1753-318X.2012.01133.x, 2012.

Imhof, M.: Analyse langfristiger Gebäudeschadendaten: Auswertung des Datenbestandes der Schadenstatistik VKF, Interkantonaler Rückversicherungsverband, Bern, Switzerland, available at: http://irv.ch/IRV/Downloads.aspx (last access: 21 September 2017), 2011.

Kipfer, A., Kienholz, C., and Liener, S.: Ein neuer Ansatz zur Modellierung von Oberflächenabfluss, in: INTERPRAEVENT 2012 - Conference Proceedings, edited by: Koboltschnig, G., Hübl, J., and Braun, J., 179-189, International Research Society INTERPRAEVENT, 2012.

Kleist, L., Thieken, A. H., Köhler, P., Müller, M., Seifert, I., Borst, D., and Werner, U.: Estimation of the regional stock of residential buildings as a basis for a comparative risk assessment in Germany, Nat. Hazards Earth Syst. Sci., 6, 541-552, https://doi.org/10.5194/nhess-6-541-2006, 2006.

Kreibich, H., Piroth, K., Seifert, I., Maiwald, H., Kunert, U., Schwarz, J., Merz, B., and Thieken, A. H.: Is flow velocity a significant parameter in flood damage modelling?, Nat. Hazards Earth Syst. Sci., 9, 1679-1692, https://doi.org/10.5194/nhess-91679-2009, 2009.

Kron, W.: Überschwemmungsüberraschung: Sturzfluten und Überschwemmungen fernab von Gewässern, Wasserwirtschaft, 6, 15 20, 2009.

Kron, W., Steuer, M., Löw, P., and Wirtz, A.: How to deal properly with a natural catastrophe database - analysis of flood losses, Nat. Hazards Earth Syst. Sci., 12, 535-550, https://doi.org/10.5194/nhess-12-535-2012, 2012.

Kundzewicz, Z. W., Kanae, S., Seneviratne, S. I., Handmer, J., Nicholls, N., Peduzzi, P., Mechler, R., Bouwer, L. M., Arnell, N., Mach, K., Muir-Wood, R., Brakenridge, G. R., Kron, W., Benito, G., Honda, Y., Takahashi, K., and Sherstyukov, B.: Flood risk and climate change: global and regional perspectives, Hydrolog. Sci. J., 59, 1-28, https://doi.org/10.1080/02626667.2013.857411, 2014. 
Ledermann, T., Herweg, K., Liniger, H., Schneider, F., Hurni, H., and Prasuhn, V.: Applying erosion damage mapping to assess and quantify off-site effects of soil erosion in Switzerland, Land Degrad. Dev., 21, 353-366, https://doi.org/10.1002/ldr.1008, 2010.

LUBW: Leitfaden kommunales Starkregenrisikomanagement in Baden-Württemberg, Landesanstalt für Umwelt, Messungen und Naturschut Baden-Württemberg (LUBW), Karlsruhe, Germany, available at: http://www.lubw.baden-wuerttemberg.de/servlet/is/ 261161 (last access: 21 September 2017), 2016.

Merz, B., Kreibich, H., Schwarze, R., and Thieken, A.: Review article "Assessment of economic flood damage", Nat. Hazards Earth Syst. Sci., 10, 1697-1724, https://doi.org/10.5194/nhess10-1697-2010, 2010.

Merz, B., Kreibich, H., and Lall, U.: Multi-variate flood damage assessment: a tree-based data-mining approach, Nat. Hazards Earth Syst. Sci., 13, 53-64, https://doi.org/10.5194/nhess-13-53-2013, 2013.

Merz, R. and Blöschl, G.: A process typology of regional floods, Water Resour. Res., 39, 1340, https://doi.org/10.1029/2002WR001952, 2003.

Moncoulon, D., Labat, D., Ardon, J., Leblois, E., Onfroy, T., Poulard, C., Aji, S., Rémy, A., and Quantin, A.: Analysis of the French insurance market exposure to floods: a stochastic model combining river overflow and surface runoff, Nat. Hazards Earth Syst. Sci., 14, 2469-2485, https://doi.org/10.5194/nhess14-2469-2014, 2014.

Pitt, M.: The Pitt Review: Learning lessons from the 2007 floods: An independent review by Sir Michael Pitt, Cabinet Office, London, UK, 2008.

Priest, S. J., Parker, D. J., Hurford, A. P., Walker, J., and Evans, K.: Assessing options for the development of surface water flood warning in England and Wales, J. Environ. Manage., 92, 30383048, https://doi.org/10.1016/j.jenvman.2011.06.041, 2011.

Romang, H., Frick, E., and Krummenacher, B.: Unwetterereignisse im November 2002, Graubünden, Schweiz, in: INTERPRAEVENT 2004 - Conference Proceedings, edited by: Stepanek, L., Kohl, B., and Markart, G., Vol. 1, 109-120, International Research Society INTERPRAEVENT, 2004.

Ruiz-Villanueva, V., Borga, M., Zoccatelli, D., Marchi, L., Gaume, E., and Ehret, U.: Extreme flood response to short-duration convective rainfall in South-West Germany, Hydrol. Earth Syst. Sci., 16, 1543-1559, https://doi.org/10.5194/hess-16-1543-2012, 2012.

Rüttimann, D. and Egli, T.: Wegleitung punktuelle Gefahrenabklärung Oberflächenwasser, Naturgefahrenkommission des Kantons St. Gallen, 2010.

Scherrer, S., Frauchiger, R., and Näf-Huber, D.: Analyse und Einordnung des Hochwassers vom 2. Mai 2013 in Schaffhausen und der Umgebung: Schwerpunkt Freudentalbach, Durach und Dorfbach Herblingen, 13/174, Scherrer AG, Hydrologie und Hochwasserschutz, Reinach, Switzerland, 2013.

Schwarze, R., Schwindt, M., Weck-Hannemann, H., Raschky, P., Zahn, F., and Wagner, G. G.: Natural hazard insurance in Europe: Tailored responses to climate change are needed, Env. Pol. Gov., 21, 14-30, https://doi.org/10.1002/eet.554, 2011.
Spekkers, M., Rözer, V., Thieken, A., ten Veldhuis, M.-C., and Kreibich, H.: A comparative survey of the impacts of extreme rainfall in two international case studies, Nat. Hazards Earth Syst. Sci., 17, 1337-1355, https://doi.org/10.5194/nhess17-1337-2017, 2017.

Spekkers, M. H., Kok, M., Clemens, F. H. L. R., and ten Veldhuis, J. A. E.: A statistical analysis of insurance damage claims related to rainfall extremes, Hydrol. Earth Syst. Sci., 17, 913-922, https://doi.org/10.5194/hess-17-913-2013, 2013.

Spekkers, M. H., Kok, M., Clemens, F. H. L. R., and ten Veldhuis, J. A. E.: Decision-tree analysis of factors influencing rainfallrelated building structure and content damage, Nat. Hazards Earth Syst. Sci., 14, 2531-2547, https://doi.org/10.5194/nhess14-2531-2014, 2014.

Spekkers, M. H., Clemens, F. H. L. R., and ten Veldhuis, J. A. E.: On the occurrence of rainstorm damage based on home insurance and weather data, Nat. Hazards Earth Syst. Sci., 15, 261-272, https://doi.org/10.5194/nhess-15-261-2015, 2015.

Steinbrich, A., Leistert, H., and Weiler, M.: Model-based quantification of runoff generation processes at high spatial and temporal resolution, Environ. Earth Sci., 75, 1423 , https://doi.org/10.1007/s12665-016-6234-9, 2016.

Thieken, A. H., Kreibich, H., Müller, M., and Merz, B.: Coping with floods: preparedness, response and recovery of flood-affected residents in Germany in 2002, Hydrolog. Sci. J., 52, 1016-1037, https://doi.org/10.1623/hysj.52.5.1016, 2007.

Uhlemann, S., Bertelmann, R., and Merz, B.: Data expansion: the potential of grey literature for understanding floods, Hydrol Earth Syst. Sci., 17, 895-911, https://doi.org/10.5194/hess-17895-2013, 2013.

van Campenhout, J., Hallot, E., Houbrechts, G., Peeters, A., Levecq, Y., Gérard, P., and Petit, F.: Flash floods and muddy floods in Wallonia: recent temporal trends, spatial distribution and reconstruction of the hydrosedimentological fluxes using flood marks and sediment deposits, Belgeo, https://doi.org/10.4000/belgeo.16409, 2015.

Ward, R. C. and Robinson, M.: Principles of hydrology, McGrawHill, London, 4th Edn., 2000.

Zhou, Q., Panduro, T. E., Thorsen, B. J., and ArnbjergNielsen, K.: Verification of flood damage modelling using insurance data, Water Sci. Technol., 68, 425-432, https://doi.org/10.2166/wst.2013.268, 2013.

Zimmermann, M., Pozzi, A., and Stoessel, F.: Vademecum - Hazard maps and related Instruments: The Swiss system and its application abroad, National Platform for Natural Hazards, Bern, Switzerland, available at: http://www.planat.ch/fileadmin/PLANAT/planat_pdf/alle_ 2012/2001-2005/PLANAT_2005_-_Vademecum.pdf (last access: 21 September 2017), 2005. 